\title{
NRDE2 negatively regulates exosome functions by inhibiting MTR4 recruitment and exosome interaction
}

\author{
Jianshu Wang, ${ }^{1,2,9}$ Jiyun Chen, ${ }^{3,9}$ Guifen Wu, ${ }^{1,2,9}$ Hongling Zhang, ${ }^{2,4,9}$ Xian Du, ${ }^{5,9}$ Suli Chen, ,,2 \\ Li Zhang, ${ }^{1,2}$ Ke Wang, ${ }^{1,2}$ Jing Fan, ${ }^{1,2}$ Shuaixin Gao, ${ }^{6}$ Xudong Wu, ${ }^{7}$ Shouxiang Zhang, ${ }^{3}$ Bin Kuai, ${ }^{1,2}$ \\ Peng Zhao, ${ }^{3}$ Binkai Chi, ${ }^{1,2}$ Lantian Wang, ${ }^{1,2}$ Guohui Li, ${ }^{7}$ Catherine C.L. Wong, ${ }^{6,8}$ Yu Zhou, ${ }^{5}$ \\ Jinsong $\mathrm{Li}^{2,4}$ Caihong Yun, ${ }^{3}$ and Hong Cheng ${ }^{1,2}$ \\ ${ }^{1}$ State Key Laboratory of Molecular Biology, CAS Center for Excellence in Molecular Cell Science, Shanghai Institute of \\ Biochemistry and Cell Biology, Chinese Academy of Sciences, University of Chinese Academy of Sciences, Shanghai 200031, \\ China; ${ }^{2}$ Shanghai Key Laboratory of Molecular Andrology, CAS Center for Excellence in Molecular Cell Science, Shanghai Institute \\ of Biochemistry and Cell Biology, Chinese Academy of Sciences, University of Chinese Academy of Sciences, Shanghai 200031, \\ China; ${ }^{3}$ Department of Biophysics, Beijing Key Laboratory of Tumor Systems Biology, School of Basic Medical Sciences, Peking \\ University Health Science Center, Beijing 100191, China; ${ }^{4}$ State Key Laboratory of Cell Biology, CAS Center for Excellence in \\ Molecular Cell Science, Shanghai Institute of Biochemistry and Cell Biology, Chinese Academy of Sciences, University of Chinese \\ Academy of Sciences, Shanghai 200031, China; ${ }^{5}$ Hubei Key Laboratory of Cell Homeostasis, College of Life Sciences, Wuhan \\ University, Wuhan 430072, China; ${ }^{6}$ Center for Precision Medicine Multi-Omics Research, Peking University Health Science \\ Center, Beijing 100191, China; ${ }^{7}$ Laboratory of Molecular Modeling and Design, State Key Laboratory of Molecular Reaction \\ Dynamics, Dalian Institute of Chemical Physics, Chinese Academy of Sciences, Dalian 116023, China; ${ }^{8}$ State Key Laboratory of \\ Natural and Biomimetic Drugs, School of Pharmaceutical Sciences, Peking University, Beijing 100191, China
}

The exosome functions in the degradation of diverse RNA species, yet how it is negatively regulated remains largely unknown. Here, we show that NRDE2 forms a 1:1 complex with MTR4, a nuclear exosome cofactor critical for exosome recruitment, via a conserved MTR4-interacting domain (MID). Unexpectedly, NRDE2 mainly localizes in nuclear speckles, where it inhibits MTR4 recruitment and RNA degradation, and thereby ensures efficient mRNA nuclear export. Structural and biochemical data revealed that NRDE2 interacts with MTR4's key residues, locks MTR4 in a closed conformation, and inhibits MTR4 interaction with the exosome as well as proteins important for MTR4 recruitment, such as the cap-binding complex (CBC) and ZFC3H1. Functionally, MID deletion results in the loss of self-renewal of mouse embryonic stem cells. Together, our data pinpoint NRDE2 as a nuclear exosome negative regulator that ensures mRNA stability and nuclear export.

[Keywords: NRDE2; the nuclear exosome; MTR4 recruitment; mRNA export]

Supplemental material is available for this article.

Received November 14, 2018; revised version accepted February 5, 2019.

The highly conserved exosome complex is the most versatile RNA surveillance and degradation machine. To achieve its full in vivo functions, the exosome associates with many cofactors, among which the RNA helicase MTR4 is essential for every aspect of nuclear exosome functions (LaCava et al. 2005; Vaňáčová et al. 2005; Wyers et al. 2005; San Paolo et al. 2009; Shcherbik et al. 2010; Lubas et al. 2011; Andersen et al. 2013; Hallais et al. 2013). In mammalian cells, MTR4 forms into spatially different complexes that link the nuclear exosome to different types of substrate RNAs. In the nucleolus, MTR4

\footnotetext{
${ }^{9}$ These authors contributed equally to this work.

Corresponding authors: hcheng@sibcb.ac.cn,yunch@hsc.pku.edu.cn,jsli@ sibcb.ac.cn, yu.zhou@whu.edu.cn

Article published online ahead of print. Article and publication date are online at http://www.genesdev.org/cgi/doi/10.1101/gad.322602.118.
}

associates with PAPD5 and ZCCHC7 to form the human TRAMP complex that is predominantly involved in rRNA processing (Lubas et al. 2011; Molleston et al. 2016). In the nucleoplasm, MTR4 interacts with RBM7 and ZCCHC8, forming the NEXT complex that is important for the degradation of promoter upstream transcripts (PROMPTs), snRNAs and a subset of pre-mRNAs with specific features (Lubas et al. 2011; Andersen et al. 2013; Hallais et al. 2013; Hrossova et al. 2015). Furthermore, MTR4 forms a complex with $\mathrm{ZFC} 3 \mathrm{H} 1$, in the presence or absence of the polyA-binding protein PABPN1, functioning in the

(C) 2019 Wang et al. This article is distributed exclusively by Cold Spring Harbor Laboratory Press for the first six months after the full-issue publication date (see http://genesdev.cshlp.org/site/misc/terms.xhtml). After six months, it is available under a Creative Commons License (Attribution-NonCommercial 4.0 International), as described at http://creativecommons.org/licenses/by-nc/4.0/. 
degradation of long processed transcripts, such as snoRNA host transcripts as well as unstable RNAs (Meola et al. 2016; Ogami and Manley 2017; Ogami et al. 2017). To date, proteins that have been identified to associate with MTR4 and the exosome all facilitate exosome functions. How the exosome is negatively regulated is largely unclear.

Recent studies revealed that the competition between RNA export factors and the exosome cofactors is important for sorting RNAs into the export or the degradation pathway (Fan et al. 2017, 2018; Giacometti et al. 2017; Silla et al. 2018). On mRNAs and lncRNAs, MTR4 physically and functionally competes with ALYREF, a key mRNA export adaptor (Strässer and Hurt 2000), for interacting with cap-binding complex (CBC) bound at the $5^{\prime}$ end of RNAs (Fan et al. 2017). At the $3^{\prime}$ end, the MTR4-ZFC3H1 complex functionally competes with ALYREF for PABPN1 (Silla et al. 2018). Nuclear RNA sorting occurs in the nucleoplasm rapidly after transcription (Fan et al. 2018; Silla et al. 2018). RNAs that have passed quality control are assembled into export-competent mRNPs in nuclear speckles (Wang et al. 2018), where exosome functions are likely inhibited (Fan et al. 2018; Wang et al. 2018). How RNA export factors outcompete the exosome in nuclear speckles is still unknown.

In this study, we demonstrate that NRDE2 forms a 1:1 complex with MTR4. Interestingly, NRDE2 mainly localizes in nuclear speckles and plays a widespread inhibitory role in MTR4 recruitment and RNA degradation. Consistent with these roles, NRDE2 depletion results in nuclear retention of a significant fraction of mRNAs. In the
NRDE2-MTR4 complex, NRDE2 shares binding pathways with other important exosome cofactors and locks MTR4 in an unusually closed conformation, suggesting that NRDE2 might disrupt MTR4 interaction with other cofactors. Indeed, NRDE2 inhibits MTR4 interaction with $\mathrm{CBC}$ and $\mathrm{ZFC} 3 \mathrm{H} 1$, correlating with its negative impact on MTR4 recruitment. Intriguingly, NRDE2 also attenuates the MTR4-exosome interaction, pinpointing NRDE2 as an exosome negative regulator. We also provide evidence that NRDE2-mediated nuclear exosome negative regulation is required for embryonic stem cell (ESC) self-renewal.

\section{Results}

\section{NRDE2 and MTR4 tightly interact in vivo and form a complex of equal stoichiometry in vitro}

In an attempt to identify MTR4-associating proteins, we detected NRDE2 by mass spectrometry (MS) (Fan et al. 2017). To validate the MS result, we carried out immunoprecipitations from RNase-treated HeLa cell lysates using MTR4 and NRDE2 antibodies. Western analysis revealed that NRDE2 and MTR4 associate with each other (Fig. 1A) (while this work was in progress, Ogami et al. 2017 also identified NRDE2 as an MTR4-associating protein). We found that the NRDE2-MTR4 association is saltresistant, as NRDE2 was efficiently coprecipitated with MTR4 even in $350 \mathrm{mM}$ salt (Fig. 1B). Together, these results indicate that NRDE2 tightly associates with MTR4 in vivo.
A
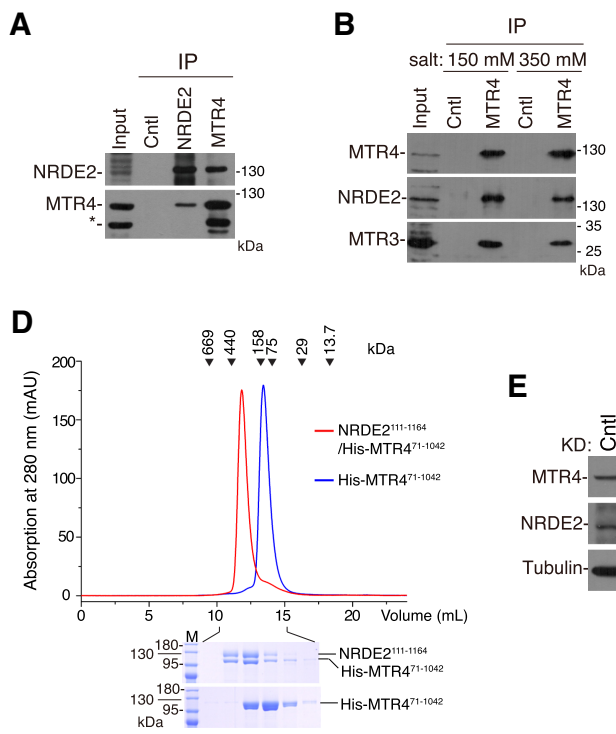

E
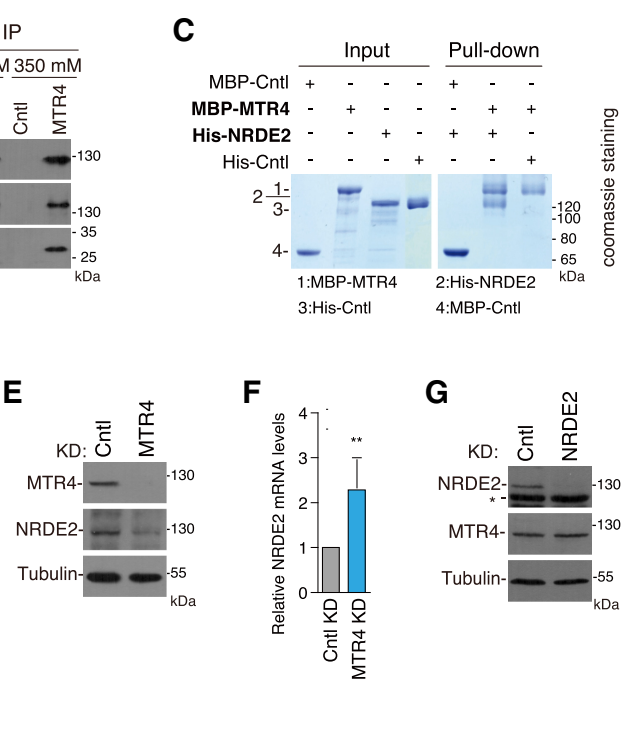

$\mathbf{F}$

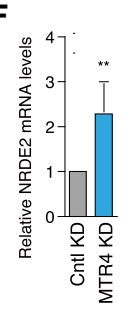

Figure 1. NRDE2 tightly interacts with MTR4 in vivo and forms a stoichiometric complex with MTR4 in vitro. $(A)$ NRDE2 and MTR4 coimmunoprecipitate each other. Immunoprecipitations using IgG and antibodies to NRDE2 and MTR4 were carried out from RNase A-treated HeLa cell lysate, followed by Western blotting with indicated antibodies. IgG was used as a negative control. $\left(^{*}\right)$ Nonspecific band. (B) MTR4 associates with NRDE2 in a salt-resistant manner. Immunoprecipitations with Cntl and the MTR4 antibody were carried out from RNase A-treated HeLa cell lysate under 150 or $350 \mathrm{mM}$ salt condition, followed by Western blotting with indicated antibodies. IgG was used as a negative control. (C) NRDE2 directly interacts with MTR4 in vitro. MBP pull-downs were carried out with His-NRDE2 $2^{111-1164}$ and MBP-MTR ${ }^{\mathrm{FL}}$. His-VCAM-1 and MBP-ALYREF were used as negative controls. The input $(12.5 \%)$ and

the bound fractions $(33 \%)$ were analyzed by SDS-PAGE followed by Coomassie staining. (D) NRDE2 and MTR4 form a complex of 1:1 stoichiometry. His-MTR $4^{71-1042}$ either in isolation or in the complex with NRDE2 $2^{111-1164}$ was separated by gel filtration chromatography. The molecular weight standard is shown above the chromatogram. The indicated fractions were further analyzed by SDS-PAGE and Coomassie staining. (E) MTR4 knockdown reduces NRDE2 protein level. Western blotting to examine protein levels of NRDE2 and MTR4 in Cntl or MTR4 knockdown cells. Tubulin was used as a loading control. (F) MTR4 knockdown does not reduce, but enhances NRDE2 mRNA level. RT-qPCRs to examine the mRNA level of NRDE2 in Cntl and MTR4 knockdown cells. NRDE2 mRNA levels were normalized to 18S rRNA. Error bar indicate standard deviation $(n=3)$. Statistical analysis was performed using Student's $t$-test. $\left(^{* *}\right) P<0.01$. $(G)$ Same as $(E)$, except that instead of MTR4, NRDE2 was knocked down. (*) Nonspecific band. 
To examine whether NRDE2 directly interacts with MTR4 in vitro, pull-downs were carried out using purified His-NRDE2 and MBP-MTR4. MBP-ALYREF (MBP-Cntl) and His-VCAM-1 (His-Cntl) served as negative controls. Significantly, Coomassie staining showed that HisNRDE2, but not His-Cntl, was apparently pulled down by MBP-MTR4, demonstrating a direct interaction of NRDE2 with MTR4 (Fig. 1C). Importantly, coexpression of untagged NRDE2 with His-MTR4 in Sf9 cells produced a well-behaved complex of NRDE2-MTR4 as revealed by gel filtration chromatography, and the two proteins were present at 1:1 stoichiometry in the complex (Fig. 1D).

The tight and direct NRDE2-MTR4 interaction promoted us to examine whether these two proteins stabilize each other. Indeed, upon MTR4 knockdown, the level of NRDE2 protein, but not that of the mRNA, was significantly reduced (Fig. 1E,F). By contrast, NRDE2 depletion did not have an apparent effect on MTR4 protein level (Fig. 1G). These results support the notion that NRDE2 requires MTR4 for maintaining its protein level.

NRDE2 is enriched in nuclear speckles and plays a widespread negative role in RNA degradation

MTR4 forms into spatially different complexes that link the exosome to distinct types of substrate RNAs (Lubas et al. 2011; Meola et al. 2016; Ogami et al. 2017). To obtain some clues about functions of the NRDE2-MTR4 complex, we examined the subcellular localization of NRDE2 in Flag-NRDE2 stable expression cells. Interestingly, NRDE2 mainly colocalized with polyA RNAs in nuclear speckles (Fig. 2A; Carter et al. 1991; Visa et al. 1993; Huang et al. 1994; Dias et al. 2010). In addition, some NRDE2 signals were also detected in the nucleoli as well as in the nucleoplasm (Fig. 2A; Supplemental Fig. S1A). Consistent with the NRDE2-MTR4 interaction, MTR4 showed moderate enrichment in nuclear speckles, although it also diffused in the nucleoplasm (Supplemental Fig. S1B).

The localization of NRDE2 in nuclear speckles is of special interest, as exosomal degradation is inhibited in these domains by unknown mechanisms (Fan et al. 2018). We speculated that NRDE2 might play an inhibitory role in exosomal RNA degradation, as none of the known MTR4/exosome-associating proteins was enriched in nuclear speckles. Consistent with this possibility, overexpression of NRDE2 resulted in elevated levels of most RNAs we examined (Fig. 2B; Supplemental Fig. S2A). To further investigate this possibility, we next examined how NRDE2 downregulation affects RNA levels genome-wide by carrying out RNA sequencing (RNA-seq) in control (Cntl) and NRDE2 knockdown cells (Fig. 2C). To assess experimental variation, the experiment was repeated twice. Considering that nuclear speckles are enriched with polyA RNAs (Carter et al. 1991; Visa et al. 1993; Huang et al. 1994; Dias et al. 2010), we focused on mRNAs and lncRNAs. In both biological replicates, we observed widespread reduced RNA levels in NRDE2 knockdown cells (Fig. 2D). Specifically, 2153 mRNAs $(18 \%)$ and 116 lncRNAs (14\%) reproducibly exhibited de- creased levels (false discovery rate $[\mathrm{FDR}]<5 \%$ ) (Fig. 2D), with the C1S mRNA shown as an example (Fig. 2E). RT-qPCR data revealed that seven out of eight RNAs that were up-regulated upon NRDE2 overexpression showed reduced levels in NRDE2 knockdown cells (Fig. $2 F$ ), suggesting that NRDE2 might play an inhibitory role in RNA degradation. However, it was also possible that the widely reduced RNA levels in NRDE2 knockdown was due to transcription down-regulation. This possibility was not supported by the P-Ser5 RNAP II chromatin immunoprecipitation (ChIP)-PCR data. In NRDE2 knockdown cells, no apparent reduction in RNAP II binding was observed with all down-regulated genes we examined (Supplemental Fig. S2B). Together, these data demonstrate a widespread role of NRDE2 in maintaining the levels of mRNAs and lncRNAs.

\section{NRDE2 globally inhibits MTR4 recruitment}

How could NRDE2 function in maintaining RNA levels? Considering the important role of MTR4 in exosome recruitment (Fan et al. 2017), we reasoned that NRDE2 might inhibit MTR4 association with RNAs. To examine this possibility, we carried out MTR4 RNA immunoprecipitations (RIPs) from Cntl and NRDE2 knockdown cells in triplicate, followed by sequencing (Fig. 2G). Using total RNA-seq data as a reference, we found that 6589 mRNAs $(60 \%)$ and 628 lncRNAs (65\%) showed significantly enhanced MTR4 association upon NRDE2 knockdown (FDR $<5 \%$; Fig. $2 \mathrm{H}$ ). RIP-seq signals of the two exemplified mRNAs, EXOSC1 and SAP30, are shown in Figure 2I.

Importantly, the vast majority of down-regulated mRNAs $(91 \%)$ and lncRNAs $(70 \%)$ in NRDE2 knockdown showed enhanced MTR4 association (Fig. 2J), suggesting that NRDE2 knockdown results in the reduction in RNA levels by enhancing MTR4/exosome recruitment. In the cells, MTR4 is much more abundant than the exosome proteins (Lubas et al. 2011). Thus, RNAs showing enhanced MTR4 association but not reduced levels might be those having recruited MTR4 but not yet undergone exosomal degradation. The enhanced MTR4 association with selected RNAs in NRDE2 knockdown cells was validated by MTR4 RIP-RT-qPCRs (Fig. 2K). Together, these data indicate that NRDE2 globally inhibits MTR4 recruitment (Fig. 2L).

\section{NRDE2 ensures efficient nuclear export of a significant fraction of $m R N A s$}

Considering the competition between MTR4 and ALYREF for RNA binding (Fan et al. 2017), the inhibitory role of NRDE2 in MTR4 recruitment raised the possibility that NRDE2 might positively impact mRNA export. To test this possibility, we prepared nuclear fractions from Cntl and NRDE2 knockdown cells (Fig. $3 \mathrm{~A})$, and carried out nuclear RNA-seq. To identify endogenous mRNAs whose nuclear export was inhibited upon NRDE2 depletion, nuclear mRNA abundance was normalized to whole-cell transcript levels. This yielded a total of 2261 candidate mRNAs that reproducibly 
A

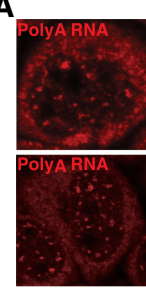

C

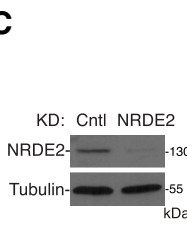

D
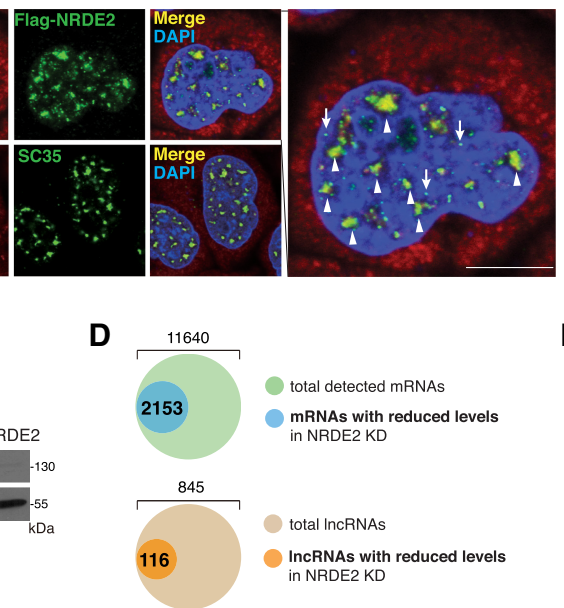

B

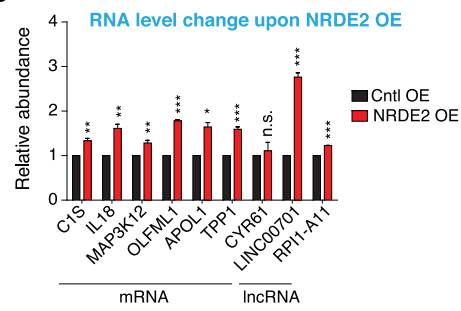

E

total detected mRNAs mRNAs with reduced levels in NRDE2 KD

total IncRNAs IncRNAs with reduced levels in NRDE2 KD

F

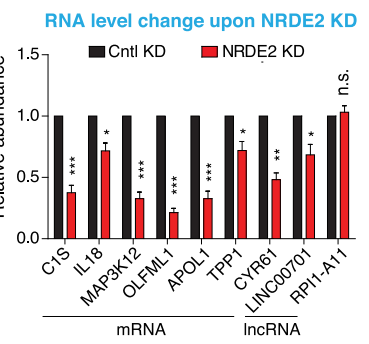

I

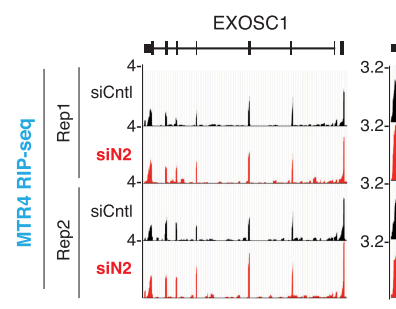

K

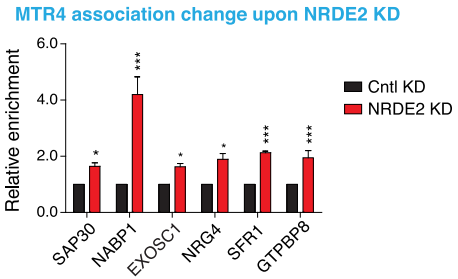

G

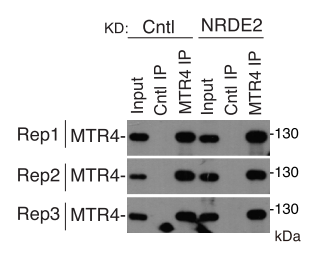

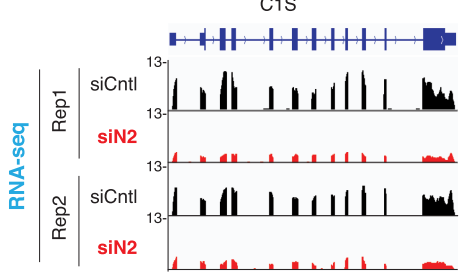

H

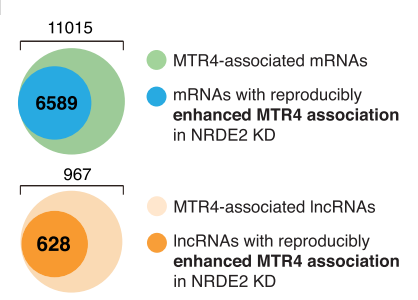

J

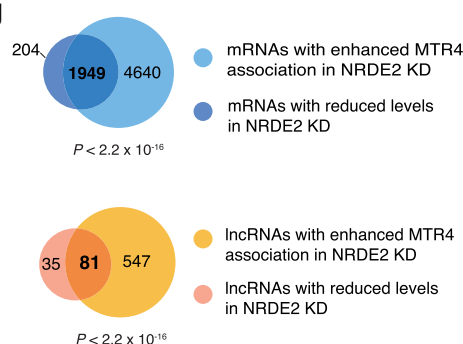

L
$P<22 \times 10^{\text {t1 }}$

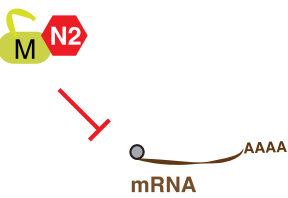

Figure 2. NRED2 is enriched in nuclear speckles and inhibits MTR4 recruitment and RNA degradation. (A) NRDE2 mainly localizes in nuclear speckles. Confocal microscopic image to show the colocalization of Flag-NRDE2 with polyA RNAs, and the colocalization of polyA RNAs with SC35, a standard nuclear speckle marker. Flag-NRDE2 signals in nuclear speckles and the nucleoplasm are marked with arrowheads and arrows, respectively. Scale bar, $10 \mu \mathrm{m}$. (B) NRDE2 overexpression leads to elevated RNA levels. RT-qPCRs to examine the levels of indicated mRNAs and lncRNAs in Cntl (eIF4AIII) and NRDE2-overexpressing cells. Error bars indicate standard deviation $(n=3)$. Statistical analysis was performed using Student's $t$-test. $\left({ }^{*}\right) P<0.05 ;\left(^{* *}\right) P<0.01 ;\left({ }^{* * *}\right) P<0.001 ;($ n.s. $) P>0.05$. $(C)$ Western analysis to examine NRDE2 knockdown efficiency. Tubulin was used as a loading control. $(D)$ The Venn diagrams depict mRNAs and lncRNAs with reproducibly reduced levels (false discovery rate $[\mathrm{FDR}]<0.05$ ) upon NRDE2 knockdown. $(E)$ Screenshot of two replicates of RNA sequencing (RNA-seq) signals of $C 1 S$. (F) RT-qPCRs to examine MTR4 associations with RNAs in Cntl and NRDE2 depleted cells. Error bars indicate standard deviation $(n=3)$. Statistical analysis was performed using Student's $t$-test. $\left({ }^{*}\right) P<0.05 ;\left({ }^{* *}\right) P<0.01 ;\left({ }^{* * *}\right) P<0.001,($ n.s. $) P>$ 0.05. $(G)$ Western analysis to examine MTR4 immunoprecipitation efficiencies from Cntl and NRDE2 knockdown cells. IgG was used as a negative control. $(H)$ The Venn diagrams depict mRNAs and lncRNAs with reproducibly enhanced MTR4 association (FDR <0.05) upon NRDE2 knockdown. (I) Screenshot of two replicates of RNA immunoprecipitation sequencing (RIP-seq) signals of the EXOSC1 and SAP30 mRNAs. (J) Venn diagrams showing overlapping of mRNAs and lncRNAs with enhanced MTR4 binding among and those with reduced levels in NRDE2 depleted cells. Statistical analysis $P$-value was used to measure the overlapping using Fisher's exact test by $\mathrm{R}$ language. The overlapping of mRNAs, $P<2.2 \times 10^{-16}$; odds ratio $=27.906$. The overlapping of lncRNAs, $P<2.2 \times 10^{-16}$, odds ratio= 52.692. (K) MTR4 RIP-RT-qPCRs to examine the association of MTR4 with RNAs in Cntl and NRDE2 depleted cells. Error bars indicate standard deviation $(n=3)$. Statistical analysis was performed using Student's $t$-test. $\left(^{*}\right) P<0.05 ;\left(^{* * *}\right) P<0.001$. $(L)$ Graphic displays that NRDE2 inhibits MTR4 binding with RNAs. 
A

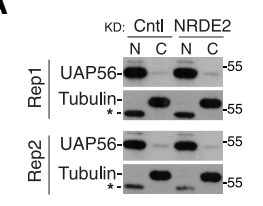

B

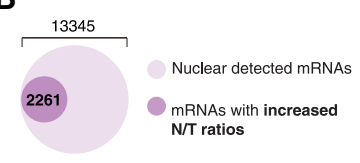

D

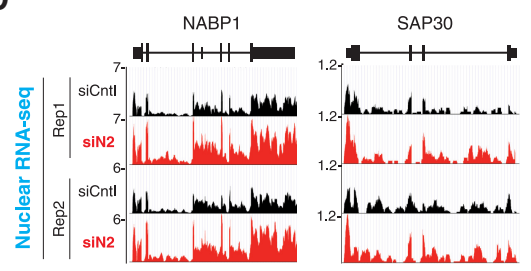

$\mathbf{F}$

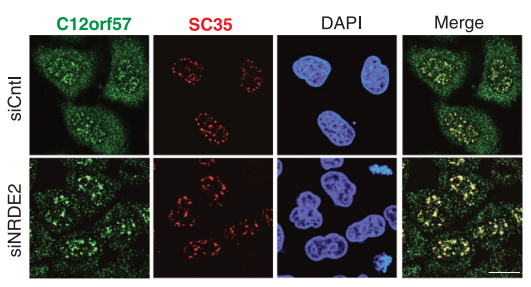

C

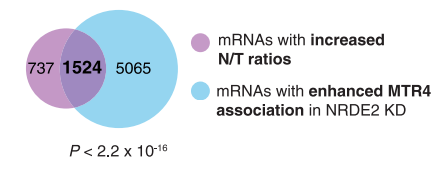

E

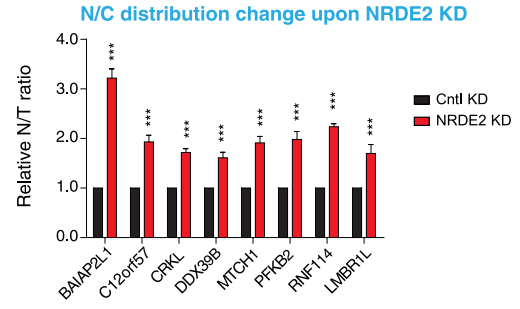

Figure 3. NRDE2 ensures efficient mRNA nuclear export. (A) Western analysis to examine the purities of nuclear fractions from Cntl and NRDE2 knockdown cells. UAP56 and Tubulin served as nuclear and cytoplasmic markers, respectively. $\left({ }^{*}\right)$ Nonspecific band. $(B)$ The Venn diagrams depict mRNAs with reproducibly nuclear retention (FDR < 0.05) upon NRDE2 knockdown. $(C)$ The Venn diagram depicts the overlapping of mRNAs with increased nuclear retention with those with reproducibly enhanced MTR4 binding in NRDE2 knockdown cells. Statistical analysis $P$-value was used to measure the overlapping using Fisher's exact test by R language. $P$-value $<2.2 \times$ $10^{-16}$; odds ratio $=5.3157$. (D) Screenshot of two replicates of nuclear RNA-seq signals of NABP1 and SAP30 mRNAs. (E) RT-qPCRs to examine nuclear/total ratios of mRNAs in Cntl and NRDE2 knockdown cells. Error bars indicate standard deviation $(n=3)$. Statistical analysis was performed using Student's $t$-test. $\left({ }^{* * *}\right) \quad P<0.001 . \quad(F) \quad$ The C12orf57 mRNA is retained in nuclear speckles in NRDE2 knockdown cells.

FISH with the transcript-specific probe and IF with the SC35 antibody were performed in Cntl and NRDE2 knockdown cells. Scale bar, $20 \mu \mathrm{m}$.

exhibited a net increase in nuclear abundance when the NRDE2 protein was depleted (Fig. 3B). Notably, among these mRNAs, 1524 (67\%) demonstrated reproducibly enhanced MTR4 binding upon NRDE2 depletion (Fig. 3C). Nuclear RNA-seq signals of NABP1 and SAP3O mRNAs are shown in Figure 3D. RT-qPCR data confirmed increased nucleocytoplasmic ratios of selected mRNAs in NRDE2 knockdown cells (Fig. 3E). Importantly, the C12orf57 mRNA, which showed enhanced MTR4 association and nuclear retention based on RNA-seq and/or RTqPCR data (Fig. 3E; Supplemental Fig. S3A), was mostly retained in nuclear speckles in NRDE2 knockdown cells, in marked contrast to its apparent cytoplasmic accumulation in Cntl cells (Fig. 3F). It was also possible that NRDE2 knockdown results in nuclear mRNA retention due to splicing inhibition. However, no apparent difference in exon and intron read population was detected between Cntl and NRDE2 knockdown cells (Supplemental Fig. S3B), and only 316 out of 2261 nuclear retained mRNAs showed increased intron retention (Supplemental Fig. S3C), refuting the possibility that NRDE2 knockdown impacts mRNA export through splicing regulation. Together, these data are in agreement with the proposal that NRDE2 ensures mRNA export by inhibiting MTR4/exosome recruitment in nuclear speckles.

\section{NRDE2 interacts with MTR4 via a conserved $N$-terminal domain}

To understand the mechanism for NRDE2 inhibiting MTR4 recruitment, we first asked how NRDE2 interacts with MTR4. NRDE2 has a predicted coiled-coil domain and a NRDE2 domain in the N-terminal part (N2-1) (Fig. 4A). Immunoprecipitations using Flag-tagged NRDE2 fragments revealed that the coiled-coil domain (N2-3), but not the rest part of NRDE2, interacts with MTR4 (Fig. 4B,C). In the coiled-coil domain, two fragments (N2-5, residues 67-123; N2-6, residues 163-266) are conserved from Schizosaccharomyces pombe to humans (Supplemental Fig. S4). Further mapping demonstrated that N2-6, but not N2-5, is required and sufficient for interacting with MTR4 (Fig. 4D). We thus named N2-6 as MTR4-inteacting domain (MID).

MTR4 contains RecA_1, RecA_2, Arch, helical bundle (HB), and WH domains (Fig. 4E). Based on MTR4 structure (Jackson et al. 2010; Weir et al. 2010), deletion of RecA_1, RecA_2, and HB would result in nonfunctional protein. Indeed, when $\Delta$ RecA_1, $\Delta$ RecA_2, or $\Delta \mathrm{HB}$ mutant was used for immunoprecipitations, none of them associated with NRDE2 (Fig. 4F). Interestingly, depletion of the Arch domain that is not predicted to disrupt MTR4 structure also diminished the NRDE2-MTR4 interaction (Fig. 4F), indicating that the Arch domain is required for MTR4 interacting with NRDE2.

\section{NRDE2 ties MTR4 in an unusually closed conformation}

We next crystalized the human NRDE2 ${ }^{\text {MID }}-$ MTR $4^{71-1042}$ complex and refined the crystal structure to $2.88 \AA$ resolution (Fig. 5A; Supplemental Fig. S5; Supplemental Table S1). For comparison, the structure of apo-MTR $4^{71-1042}$ was also determined (Fig. 5B). MTR4, both in complex with NRDE2 ${ }^{\mathrm{MID}}$ and in apo-state, exhibits the typical 
A

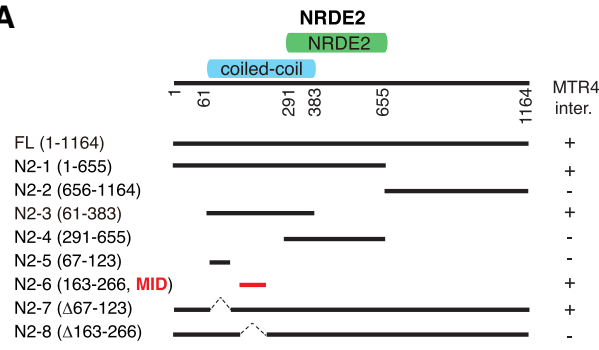

C

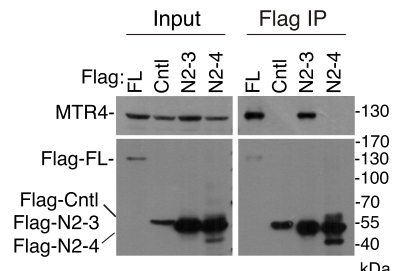

E

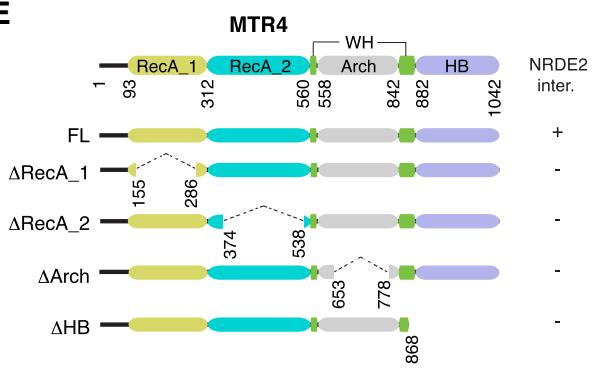

B
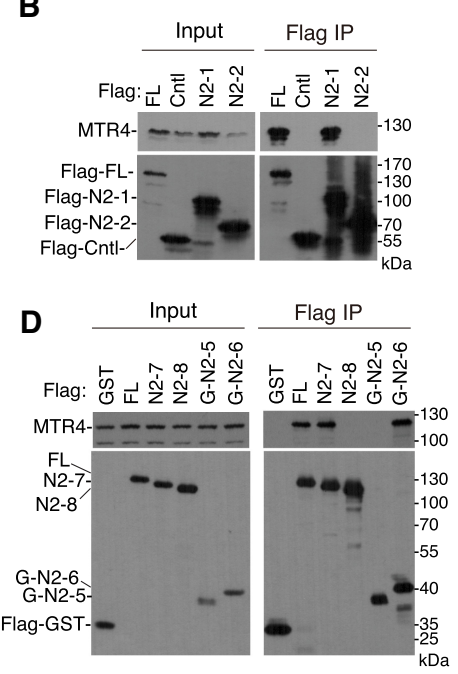

$\mathbf{F}$

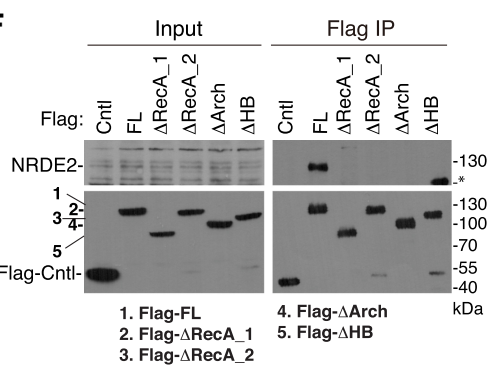

NRDE2 negatively regulates exosome functions

Figure 4. NRDE2 interacts with MTR4 via a conserved $\mathrm{N}$-terminal domain. (A) Domain schematic representation of NRDE2. NRDE2 fragments used for mapping MTR4-interacting domains (MIDs) are illustrated. $(B)$ The N-terminal, but not the Cterminal, fragment of NRDE2, associates with MTR4. Immunoprecipitations with Cntl or the Flag antibody were carried out from HeLa cell lysates expressing Flagtagged eIF4AIII (Cntl), the full-length (FL) or fragments (N2-1 and N2-2) of NRDE2, respectively. IgG was used as a negative control. Western blotting was performed with indicated antibodies. $(C)$ The predicted coiled-coil domain, but not the NRDE2 domain, associates with MTR4. Same as in $(B)$, except that instead of N2-1 and N2-2, N2-3 and N2-4 were used. $(D)$ The fragment of N2-6 is sufficient and necessary for NRDE2 interacting with MTR4. Same as in $(B)$, except that instead of N2-1 and N22, N2-5 to N2-8 fragments were used. Note that N2-5 and N2-6 fragments were Flag- and GST-tagged to obtain good expression. (E) Domain schematic representation of MTR4. MTR4 fragments used for mapping NRDE2-interacting domains are illustrated. $(F)$ Deletion of any MTR4 functional domain results in the loss of interaction with NRDE2. Immunoprecipitations were carried out using the Flag antibody from HeLa cell lysates expressing Flag-tagged eIF4AIII (Cntl), the full-length (FL) or truncation mutants of MTR4, followed by Western blotting with indicated antibodies. (*) Nonspecific band.

architecture composed of the four-domain helicase core (RecA_1, RecA_2, HB, and WH) and an Arch domain (Fig. 5A,B; Supplemental Fig. S6A). The MTR4-interacting domain (MID) binds on the surface of MTR4, wrapping it from the Arch domain to HB and RecA_2 domains (Fig. 5A). Although the helicase core structure of MTR4 in the complex closely resembles that in apo-MTR4 as well as other reported MTR4 structures, the orientation of the Arch domain is apparently different (Fig. 5A,B; Supplemental Fig. S6A; Weir et al. 2010; Falk et al. 2014, 2017; Taylor et al. 2014; Conrad et al. 2016; Puno and Lima 2018; Schuller et al. 2018; Weick et al. 2018). Specifically, the Arch domain rotates and approaches the helicase core, resulting in an unusually "closed" conformation (Fig. 5A, B; Supplemental Fig. S6A). To validate the key interactions revealed by the structural data, we constructed a set of NRDE2 and MTR4 mutants and carried out coimmunoprecipitation experiments. These data demonstrate that NRDE2 mainly binds on the MTR4 Arch via residues 163-207, and conserved residues Phe163/Asp166/ Tyr187/Arg189 are important for this binding (Fig. 5C). Notably, mutations in these four residues resulted in the loss of RNA stabilizing effect of NRDE2 overexpression (Supplemental Fig. S6B). Furthermore, NRDE2 $211-258$ that binds on RecA_2 and HB domains also makes contribution to MTR4 interaction (Fig. 5C). These results suggest that NRDE2 binding on the Arch domain and the helicase core ties MTR4 into a closed conformation. In line with this view, mutations in conserved residues of Arg658, Arg743, and Glu697 in the Arch domain and Phe989/Glu990 in the HB domain disrupted MTR4 interaction with NRDE2 (Fig. 5D,E, insets 1 and 2; Supplemental Fig. S7).

The closed conformation of MTR4 might inhibit its RNA binding properties. To examine this possibility, we carried out gel shift experiments using purified MTR4 or NRDE2 ${ }^{\text {MID }}$-MTR 4 complex. However, MTR4 in the complex with NRDE2 $2^{\mathrm{MID}}$ exhibited apparently enhanced binding affinity (approximately eightfold), as compared to MTR4 in isolation (Supplemental Fig. S8A). Consistent with this, the helicase activity of MTR4 was also stimulated (approximately eightfold) by NRDE2 ${ }^{\mathrm{MID}}$ (Supplemental Fig. S8B). How NRDE2 enhances the in vitro RNA-binding and helicase activity of MTR4 remains unknown (see the Discussion). Nevertheless, these data do not support the notion that NRDE2 precludes MTR4 recruitment in the cells by directly inhibiting its RNA binding affinity.

\section{NRDE2 occupies key residues of MTR4}

How does it inhibit MTR4 recruitment in vivo? Many exosome cofactors share a consensus motif-AIM (Arch-interacting motif, LFX $\phi D \mid$, through which they form 
A

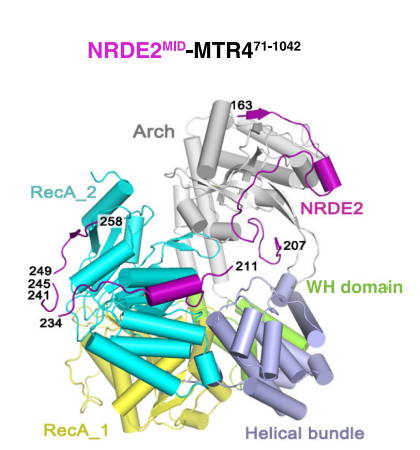

C

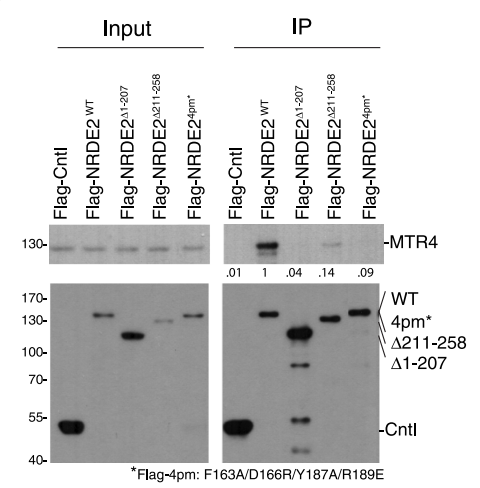

B

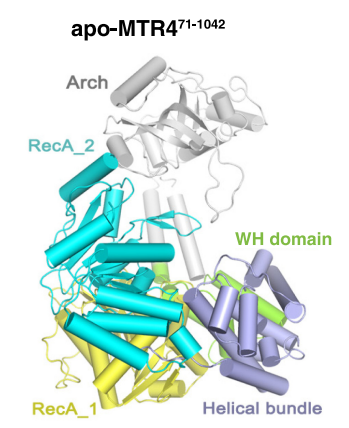

D

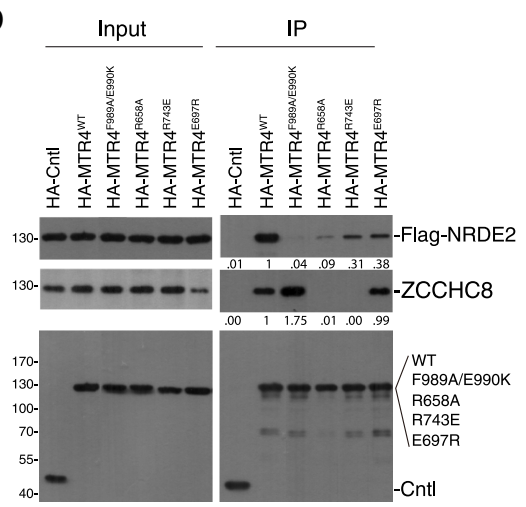

E
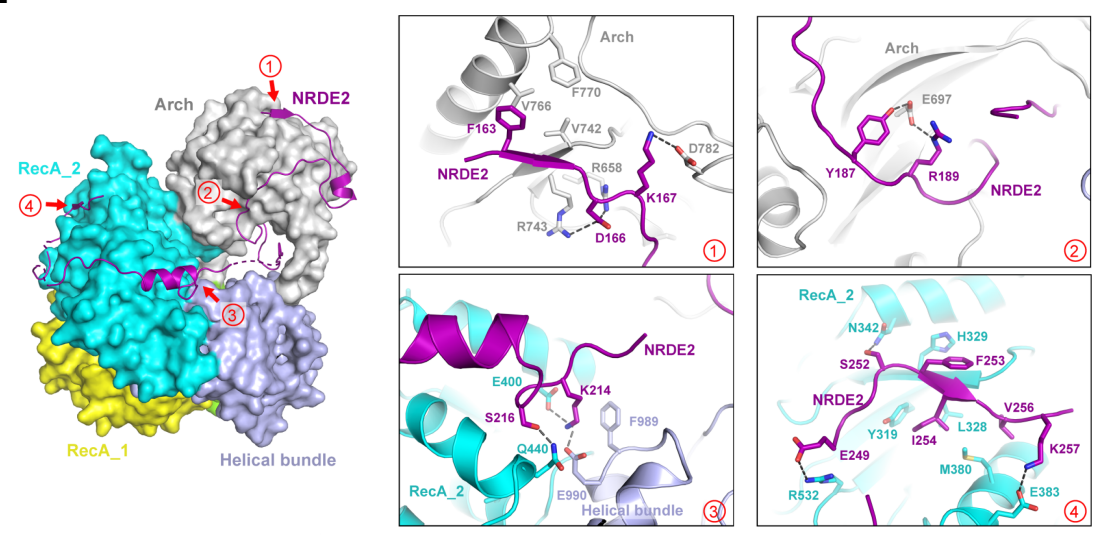

Figure 5. NRDE2 $2^{\mathrm{MID}}$ interacts with key residues of MTR4 and ties it in an unusually closed conformation. $(A, B)$ Overall structures of NRDE2 $2^{\text {MID }}$-MTR4 $4^{71-1042}$ and apoMTR $4^{71-1042}$. The proteins are shown as cartoons with helices in cylindrical presentation. The Arch, RecA_1, RecA_2, HB, and WH domains are shown in gray, yellow, cyan, lightblue, and green, respectively. NRDE2 is shown in purple. (C) Identification of key residues for NRDE2 interacting with MTR4. Flag immunoprecipitations were carried out from RNase A-treated HeLa cell lysates expressing Flag-tagged Cntl, wild-type or mutant forms of NRDE2, followed by Western blotting with Flag and MTR4 antibodies. (D) Identification of key residues for MTR4 interacting with NRDE2. HA immunoprecipitations were carried out from RNase A-treated $\mathrm{HeLa}$ cell lysates stably expressing Flag-NRDE2 together with HA-tagged SLBP (Cntl), wild-type or mutant forms of MTR4, followed by Western blotting with HA, ZCCHC8 and Flag antibodies. (E) Key interactions between MTR $4^{71-1042}$ and NRDE2 ${ }^{\text {MID }}$. Insets 1, 2, 3, and 4 are close views. Key residues participating in the interactions are shown as sticks, and polar interactions are indicated by black dashes. distinct complexes with MTR4 (Thoms et al. 2015; Falk et al. 2017). We identified a conserved AIM-like motif in NRDE2 (residues 163-166, FRTD) that binds to MTR4 at the same sites and through the same interactions as the typical AIMs do (Fig. 5E, inset 1; Supplemental Fig. S4; Falk et al. 2014, 2017), suggesting that NRDE2 binding might be incompatible with other AIM-containing proteins. In support of this possibility, although mutation in MTR4 Arg658 and Arg743 that contact to the AIM reduced both NRDE2-MTR4 and ZCCHC8-MTR4 interactions, mutations in MTR4 Phe989A/Glu990K that contact to residues other than AIM reduced its interaction with NRDE2, but enhanced that with ZCCHC8 (Fig. 5D). In addition, on MTR4 helicase core, NRDE2 also binds in the same pathways as Air2 and Trf4 (Supplemental Fig. S7A, insets 3 and 4; Falk et al. 2014). These structural data raised the possibility that NRDE2 might prevent
MTR4 from binding with other proteins, and thereby inhibit MTR4 recruitment and RNA degradation.

\section{NRDE2 inhibits MTR4 interaction with CBC, ZFC3H1 as well as the exosome}

To examine how NRDE2 affects the MTR4 interactome, we carried out MTR4 immunoprecipitations in NRDE2overexpressing and knockdown cells, followed by semiquantitative MS (Fig. 6A). MTR4 association with many proteins was impacted by the altered NRDE2 expression level (Supplemental Dataset S1). Among these, CBC components, CBP80 and ARS2, as well as ZFC3H1, attracted our attention (Fig. 6A), as they are important for MTR4 recruitment (Meola et al. 2016; Fan et al. 2017; Giacometti et al. 2017; Silla et al. 2018). Significantly, NRDE2 
overexpression reduced, whereas its knockdown enhanced, the enrichments of these proteins in the MTR4 immunoprecipitate, indicating that NRDE2 inhibits MTR4 interaction with both CBC and ZFC3H1 (Fig. 6A). These data are in line with the notion that NRDE2 inhibits MTR4 association with mRNAs and lncRNAs by inhibiting its recruitment via $\mathrm{CBC}$ and $\mathrm{ZFC} 3 \mathrm{H} 1$. Intriguingly, we found that the associations of MTR4 with most exosome components were also apparently inhibited by NRDE2 overexpression and enhanced by its knockdown (Fig. 6A). Note that no protein has been identified to inhibit MTR4 interaction with the exosome. These altered interactions with MTR4 in NRDE2-overexpressing and knockdown cells were validated by immunoprecipitation-Western data (Fig. 6B,C; Supplemental Fig. S8C). Together, these data demonstrate that NRDE2 inhibits MTR4 interactions with the exosome as well as its key recruiters, $\mathrm{CBC}$ and ZFC3H1, providing mechanistic explanation for its negative impacts on MTR4 recruitment and RNA degradation (Fig. 6D).

\section{NRDE2-mediated exosome negative regulation is required for maintaining ESC pluripotency}

To study whether the role of NRDE2 in negatively regulating exosome is biologically relevant, we depleted the NRDE2 ${ }^{\mathrm{MID}}$ (residues 171-275 in mouse NRDE2; Supplemental Fig. S9) using CRISPR-Cas9-based gene editing in mouse ESCs. Using two pairs of sgRNAs, we obtained two $\triangle$ MID homogenous cells, in which either the
mNRDE2 $2^{170-309}\left(\triangle \mathrm{MID \# 1)}\right.$ or mNRDE2 $2^{138-309}(\Delta \mathrm{MID \# 2)}$ was deleted without disrupting the downstream reading frame (Fig. 7A; Supplemental Figs. S9, S10). Interestingly, homogenous MID depletion resulted in the loss of typical ESC morphology and alkaline phosphatase (AP) staining (Fig. 7B,C). In addition, their depletion also increased the expression of lineage markers, such as $C d x 2$, Gata3, Gata4, Gata6, and Fgf5, determined by RT-qPCRs (Fig. 7D). These results indicate that MID is required for maintaining ESC self-renewal.

\section{Discussion}

The exosome has a central role in several aspects of RNA biogenesis, including RNA maturation, degradation and surveillance. Since its discovery, many cofactors and associating proteins that facilitate exosome functions have been identified (LaCava et al. 2005; Vaňáčová et al. 2005; Wyers et al. 2005; San Paolo et al. 2009; Shcherbik et al. 2010; Lubas et al. 2011; Andersen et al. 2013; Hallais et al. 2013). However, how this powerful machinery is negatively regulated remains largely unknown. Our study demonstrates that NRDE2 is a negative regulator of the nuclear exosome (see model in Fig. 7E). We show that NRDE2 forms a complex with MTR4 in nuclear speckles, where it impedes MTR4 recruitment and exosome interaction, and thereby ensures the stability and nuclear export of mRNAs. In the absence of NRDE2 binding, MTR4 is unlocked, binds on the RNAs and recruits the
A

\begin{tabular}{|c|c|c|}
\hline \multicolumn{3}{|c|}{ MTR4 associating proteins } \\
\hline protein & $\begin{array}{l}\text { NRDE2 } \\
\text { OE/Cnt| }\end{array}$ & $\begin{array}{l}\text { NRDE2 } \\
\text { KD/Cnt }\end{array}$ \\
\hline NRDE2 & 13.3 & 0 \\
\hline \multicolumn{3}{|c|}{ Exosome } \\
\hline RRP6 & 0.83 & 1.45 \\
\hline RRP40 & 0.64 & 1.01 \\
\hline MTR3 & 0.66 & 5.02 \\
\hline RRP43 & 0.7 & 1.07 \\
\hline CLS4 & 0.81 & 1.22 \\
\hline RRP4 & 0.84 & 1.55 \\
\hline RRP46 & 0.91 & 2.31 \\
\hline RRP44 & 2.1 & -- \\
\hline RRP45 & 0.7 & 0.98 \\
\hline RRP42 & 0.67 & 1.11 \\
\hline RRP41 & 0.66 & 1.5 \\
\hline \multicolumn{3}{|c|}{ MTR4 recruiting factors } \\
\hline CBP80 & 0.29 & -- \\
\hline ARS2 & 0.29 & 1.79 \\
\hline $\mathrm{ZFC} 3 \mathrm{H} 1$ & 0.78 & 155 \\
\hline
\end{tabular}

B

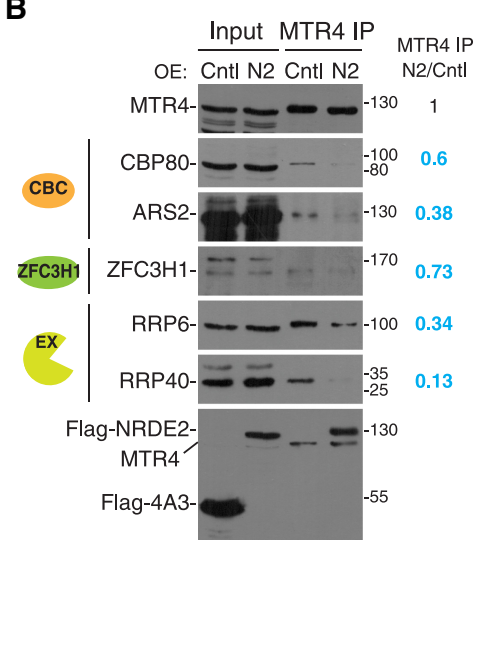

C

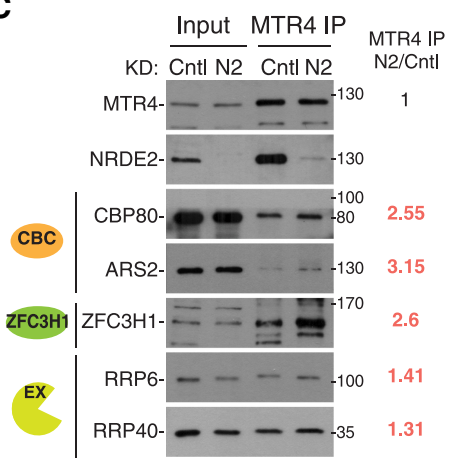

D

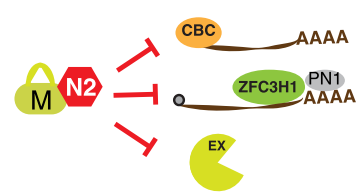

Figure 6. NRED2 disrupts MTR4 interactions with $\mathrm{CBC}$, ZFC3H1 and the exosome. (A) Semiquantitative mass spec data revealed that NRDE2 negatively impacts MTR4 interaction with the exosome, CBC and ZFC3H1. (B) Immunoprecipitation-Western data confirmed that altered association of MTR4 with ZFC3H1 as well as CBC and exosome components. Immunoprecipitations using the MTR4 antibody were carried out from RNase A-treated HeLa cell lysates overexpressing Flag-eIF4AIII (Cntl) or Flag-NRDE2, followed by Western blotting with indicated antibodies. The averaged ratios $(n=3)$ of abundance of each protein present in MTR4 immunoprecipitate from NRDE2-overexpressing versus Cntl cells are shown at the right. $(C)$ Same as $(B)$, except that NRDE2 and Cntl knockdown cells were used for immunoprecipitations. The averaged ratios $(n=2)$ of abundance of each protein present in MTR4 immunoprecipitate from NRDE2 knockdown versus Cntl cells are shown at the right. (D) Graphic displays that NRDE2 disrupts MTR4 interaction with the exosome as well as $\mathrm{CBC}$ and $\mathrm{ZFC} 3 \mathrm{H} 1$ bound at the $5^{\prime}$ and $3^{\prime}$ end of the RNA. 
A

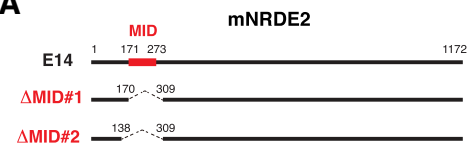

C

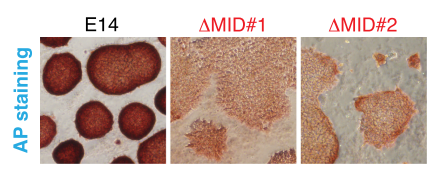

E

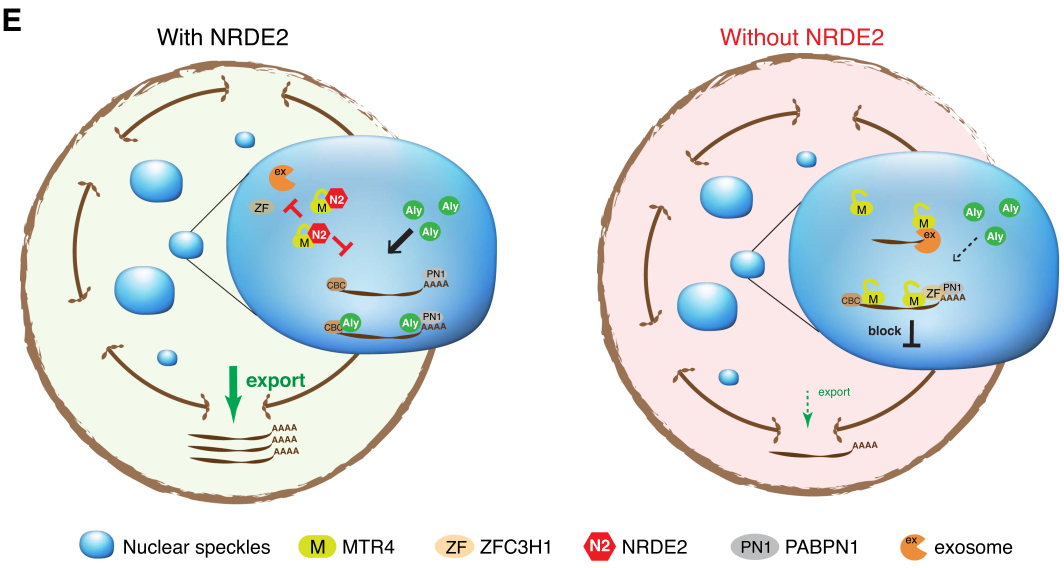

B

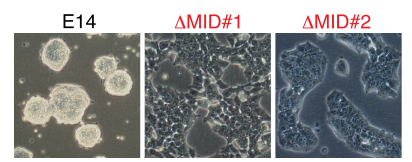

D

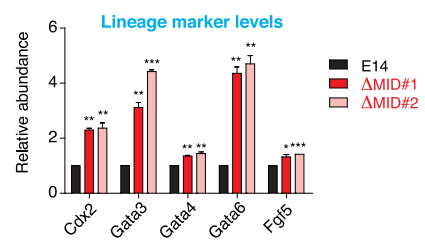

Figure 7. MID depletion results in the loss of self-renewal of mouse ESC. (A) Schematic illustration of $\triangle \mathrm{MID}$ mutants. (B) ESC morphology of E14, $\triangle \mathrm{MID \# 1}$ and $\triangle \mathrm{MID \# 2}$ cells. (C) AP staining of E14, $\triangle \mathrm{MID} \# 1$ and $\triangle \mathrm{MID} \# 2$ cells. $(D)$ Lineage marker expression in E14, $\triangle \mathrm{MID \# 1}$ and $\Delta$ MID\#2 cells. Relative expression levels of lineage markers to GAPDH were determined by RTqPCR. Error bars indicate standard deviation $\mid n=$ 3). Statistical analysis was performed using Student's $t$-test. $\left(^{*}\right) P<0.05 ;\left({ }^{* *}\right) P<0.01 ;\left({ }^{* * *}\right) P<$ 0.001. (E) A model for NRDE2 negatively regulates MTR4/exosome. See details in the text. exosome, resulting in enhanced mRNA nuclear retention and degradation.

\section{Negative roles of NRDE2 in MTR4 recruitment and exosomal degradation}

MTR4 plays essential roles in all aspects of nuclear exosome functions by recognizing exosome target RNAs, recruiting them to the exosome, and facilitating their channeling into the exosome (LaCava et al. 2005; Vaňáčová et al. 2005; Wyers et al. 2005; Houseley et al. 2006; Vasiljeva and Buratowski 2006; San Paolo et al. 2009; Shcherbik et al. 2010; Lubas et al. 2011; Andersen et al. 2013; Hallais et al. 2013; Fan et al. 2017; Schuller et al. 2018; Weick et al. 2018). Thus, blocking MTR4 seems to be an economic and efficient way to inhibit nuclear exosome functions. Our study here reveals that NRDE2 has a two-layer inhibitory role in exosome functions (See model in Fig. 7E). On the one hand, NRDE2 binding inhibits MTR4 interaction with $\mathrm{CBC}$ and $\mathrm{ZFC} 3 \mathrm{H} 1$, both of which are important for MTR4 recruitment (Meola et al. 2016), resulting in reduced MTR4/exosome recruitment. On the other hand, NRDE2 prevents MTR4 from interacting with the exosome, further ensuring that even in the case that MTR4 recruitment did occur, exosome cannot be recruited for RNA degradation.

How could NRDE2 inhibit MTR4 interaction with so many proteins? NRDE2 ${ }^{\mathrm{MID}}$ occupies MTR4 residues/ interfaces critical for binding with other proteins (Falk et al. 2014, 2017; Thoms et al. 2015). For example,
NRDE2 directly contact to the highly conserved MTR4 Arg658 that is required for MTR4 interaction with NRDE2, ZCCHC8, Nop53, and Air2 (Falk et al. 2014; Thoms et al. 2015). Furthermore, in the complex with NRDE2, MTR4 is in an unusually closed conformation that might be infeasible for binding with many proteins, including the exosome. Based on the modeling of an exosome/MTR4/pre-60S super complex (Supplemental Fig. S11A; Schuller et al. 2018), Rrp6 and Rrp47 form a helices bundle that binds to MTR4 on both the Arch and the helicase core (Supplemental Fig. S11A). In the NRDE2-MTR4 complex, the closed MTR4 conformation would abolish the interaction between MTR4 Arch domain and the Rrp6/47 helices bundle, and thereby decrease MTR4 interaction with the exosome (Supplemental Fig. S11B) and pre-60S (Supplemental Fig. S12). Also, the closed Arch domain would also apparently impede its interaction with the preribosome due to obvious steric hindrance (Supplemental Fig. S12; Schuller et al. 2018). In addition to RRP6/47, MTR4 is also recruited to the exosome by MPP6. Although based on the recently reported MTR4exosome structure (Weick et al. 2018), NRDE2 ${ }^{\mathrm{MID}}$ itself does not seem to interfere with the interaction of MPP6 (Supplemental Fig. S13), it is possible that the rest part of NRDE2 (residues 1-162; 267-1164) might hinder this interaction. Ski2 is the cytoplasmic counterpart of MTR4 that displays a similar structure (Anderson and Parker 1998; Halbach et al. 2012; Schmidt et al. 2016). It would be interesting to investigate whether a NRDE2-like factor negatively regulates the cytoplasmic exosome functions. 


\section{NRDE2 ensures efficient nuclear mRNA export}

Why do cells require a negative regulator of exosome functions? Accumulating evidence suggests that the competition between the nuclear export and the degradation machinery is important for sorting nascent RNAs for export or degradation (Fan et al. 2017, 2018; Giacometti et al. 2017; Silla et al. 2018). Newly transcribed RNAs that have passed quality control in the nucleoplasm enter nuclear speckles to assemble into exportcompetent mRNPs (Mor et al. 2016; Fan et al. 2018; Silla et al. 2018; Wang et al. 2018). Considering that MTR4/ exosome are not excluded from nuclear speckles, local mechanisms are needed to preclude MTR4 from competing with ALYREF for RNAs in these subnuclear domains. Our data showing that NRDE2 is concentrated in nuclear speckles and inhibits MTR4 recruitment suggest that NRDE2 facilitates ALYREF recruitment and mRNA export. In support of this view, depletion of NRDE2 results in nuclear retention of one-sixth of mRNAs.

We provide evidence that NRDE2-mediated exosome negative regulation is of biological importance, as MID depletion results in the loss of ESC self-renewal. How NRDE2 ensures ESC self-renewal remains unknown. Nevertheless, these data do support that the view that NRDE2-mediated negative regulation of the exosome is of significant biological importance.

A recent study reported that both NRDE2 and MTR4 negatively affects DNA damage responses in mammalian cells (Richard et al. 2018), indicating that NRDE2 could cooperate with MTR4 in some other biological processes that are independent of $\mathrm{CBC} / \mathrm{ZFC} 3 \mathrm{H} 1$ and the exosome. In line with this, similar to previous finding with ZCCHC8 (Puno and Lima 2018) and Trf4/Air2 (Jia et al. 2012), NRDE2 binding enhances in vitro RNA-binding properties and helicase activity of MTR4. How these proteins, including NRDE2, enhance MTR4 helicase activity remains unknown. Based on the data that NRDE2 enhances RNA binding affinity and helicase activity of MTR 4 by similar fold, we speculate that this might be due to enhanced RNA binding ability. Together with studies reported by Puno and Lima (2018) and Jia et al. (2012), we speculate that MTR4 alone exhibiting limited RNA binding ability might be due to the hindrance of the flexible Arch domain. When in complex with ZCCHC8, Trf4/ Air2 or NRDE2, the Arch domain is positioned at more favorable orientations for RNA binding. Further studies are required to investigate this possibility.

\section{Materials and methods}

Plasmids and antibodies

To construct the expression plasmids of Flag-eIF4AIII, FlagMTR4, Flag-NRDE2 ${ }^{\mathrm{FL}}$, or fragments, the corresponding sequences were cloned into Flag-pHAGE. To construct HA-MTR4 and HA-SLBP, MTR4 and SLBP coding sequences were inserted into Flag-pHAGE with Flag replaced by HA. The deletion or point mutation expression plasmids of MTR4 and NRDE2 were constructed by mutagenesis using the KOD-Plus-Mutagenesis Kit
(Takara). To construct Flag-GST-tagged NRDE2 fragments, GST was first cloned into the p3xFlag plasmid, followed by insertion of NRDE2 fragments. MTR $4^{71-1042}$, MTR $4^{134-1042}$, and NRDE2 ${ }^{111-1164}$ were cloned into pFastBac HT A with or without an N-terminal 6xHis-tag followed by a tobacco etch virus (TEV) protease cleavage site. NRDE2 $2^{\mathrm{MID}}$ was cloned into a modified pET28a vector with an N-terminal 6xHis-SUMO-tag followed by ubiquitin-like-specific protease 1 (Ulp1) protease cleavage site. To generate CRISPR-Cas9 plasmids for gene editing, sgRNAs of target genes were synthesized, annealed, and ligated to the pX330-mCherry plasmid.

The UAP56, CBP80, MTR4, MTR3, and ARS2 antibodies were described previously (Chi et al. 2013; Fan et al. 2017). Primary antibodies used for Western blotting included Flag (1:1000; SigmaAldrich), HA (1:1000; Sigma-Aldrich), NRDE2 (1:500; ProteinTech), RRP6 (1:1000; Sigma-Aldrich), Tubulin (1:1000; Sigma-Aldrich), ZFC3H1 (1:500; Novus), and ZCCHC8 (1:1000; Abcam). Primary antibodies used for immunofluorescence, including Nucleolin (1:200; Abcam), Flag (1:200; Sigma-Aldrich), and SC35 (1:2000; Sigma-Aldrich), were purchased. The P-Ser5 RNAP II antibody (1:200; Abcam) used for ChIP was purchased. The Digoxin (1:200; Roche) antibody used for FISH to detect the endogenous C12orf57 mRNA was purchased. IgG was purchased from Santa Cruz Biotechnology. Alexa Fluor 546- and Alexa Fluor 488-conjugated secondary antibodies were purchased from Life Technologies.

\section{Cell culture and transfection}

HeLa and 293FT cells were cultured in Dulbecco's modified Eagle's medium supplemented with $10 \%$ fetal bovine serum (FBS) and penicillin/streptomycin. E14Tg2a (E14) cells were obtained from the Core Facility for Stem Cell Research and cultured in DMEM medium supplemented with 15\% FBS, 1000 U/mL leukemia inhibitory factor (LIF), $3 \mu \mathrm{M}$ CHIR99021, and $1 \mu \mathrm{M}$ PD0325901.

For siRNA transfection, HeLa cells seeded in six-well plate were transfected with 1.625 pmol of siRNA per well using lipofectamine RNAi Max (Invitrogen) following the manufacturer's protocol. DNA transfection was performed using Lipofectamine 2000 (Invitrogen) following the manufacturer's protocol. The siRNA, shRNA, and sgRNA sequences are listed in Supplemental Table S2.

\section{RNA extraction and RT-qPCR}

Total RNA was extracted using TRI reagent (Sigma-Aldrich) and treated with RNase-free RQ1 DNase I (Promega) to remove genomic DNA. Random primer was used for reverse transcription by M-MLV reverse transcriptase (Promega). Quantitative PCR was carried out using SYBR qPCR Super Mix Plus (Novoprotein) according to the manufacturer's instruction. The primers used for qPCR were listed in Supplemental Table S3.

\section{Protein immunoprecipitations}

Antibodies were covalently cross-linked to nProtein A Sepharose (GE Healthcare) by dimethyl pimelimidate. Cells were lysed in the lysis buffer (20 mM Tris at $\mathrm{pH} 7.4,150 \mathrm{mM} \mathrm{NaCl}, 2 \mathrm{mM}$ EDTA at $\mathrm{pH} 8.0,0.1 \%$ Triton, $1 \mathrm{mM}$ DTT, $1 \mathrm{mM}$ PMSF, protease inhibitor [Roche]) and gently sonicated. The lysates were centrifuged and treated with RNase A for $20 \mathrm{~min}$ at $30^{\circ} \mathrm{C}$, followed by incubation with antibody-cross-linked beads overnight at $4^{\circ} \mathrm{C}$. The mixtures were washed with the lysis buffer six times, and the proteins were eluted with SDS loading buffer. 
Immunofluorescence, FISH, and AP staining

Cells were fixed with $4 \%$ PFA in $1 \times$ PBS for 15 min, permeabilized with $0.5 \%$ Triton in $1 \times$ PBS for $5 \mathrm{~min}$, and then blocked in blocking buffer $(2 \mathrm{mg} / \mathrm{mL}$ BSA, $0.1 \%$ Triton, $1 \times$ PBS). Cells were incubated with the primary antibody diluted in blocking buffer for $1 \mathrm{~h}$ at room temperature, followed by incubation with the Alexa-546or Alexa-488-labeled second antibodies for $1 \mathrm{~h}$ and DAPI staining. Cells were imaged by confocal microscope (Olympus FV1200). FISH to detect polyA RNAs using a high performance liquid chromatography-purified Alexa 548-conjugated oligo dT (70) probe was performed as previously described (Chi et al. 2014).

To detect the endogenous mRNA with SC35 simultaneously, HeLa cells were fixed with $3.6 \%$ formaldehyde plus $10 \%$ acetic acid in PBS (pH 7.4) for 20 min, followed by three washes with $1 \times$ PBS and permeabilized with $1 \times$ PBS $/ 0.1 \%$ Triton $/ 2 \mathrm{mM}$ Vanadyl Ribonucleoside Complex (VRC) for $15 \mathrm{~min}$. The cells were incubated with specific probes that were labeled with digoxin for $16 \mathrm{~h}$ at $50^{\circ} \mathrm{C}$. After extensive wash, cells were incubated with the digoxin, and SC35 antibodies were diluted in blocking buffer ( $1 \times$ PBS, $0.1 \%$ Triton, $2 \mathrm{mg} / \mathrm{mL}$ BSA) for $1 \mathrm{~h}$. After three washes with $1 \times$ PBS and incubation with the Alexa-488-labeled anti-sheep antibody for $1 \mathrm{~h}$, the cells were washed with $1 \times$ PBS three times and incubated with the Alexa-546-labeled antimouse antibody for another $1 \mathrm{~h}$, followed by DAPI staining and three washes with $1 \times$ PBS.

For AP staining, ESCs were fixed with $4 \%$ paraformaldehyde (PFA) for $10 \mathrm{~min}$ at room temperature, followed by staining with Fast Red TR Salt 1,5-naphthalenedisulfonate salt kit (Sigma-Aldrich) according to the manufacturer's instruction.

\section{Gel filtration}

His-MTR $4^{71-1042}$ and untagged NRDE2 $2^{111-1164}$ were coexpressed in Sf9 insect cells and affinity purified using Chelating Sepharose column (GE Healthcare) charged with $\mathrm{Ni}^{2+}$. The proteins were further purified by a Mono Q (GE Healthcare) to remove free NRDE2 $2^{111-1164}$. Finally, the protein was concentrated and loaded onto a Superdex 200 10/300 gel-filtration column (GE Healthcare) equilibrated with buffer containing $20 \mathrm{mM}$ Tris (pH 8.0), $150 \mathrm{mM} \mathrm{NaCl}, 1 \%$ (v/v) glycerol, and $1 \mathrm{mM}$ TCEP.

\section{MBP pull-downs}

For each pull-down reaction, $8 \mu \mathrm{g}$ of MBP-tagged proteins and $8 \mu \mathrm{g}$ of His-tagged proteins were added to $20 \mu \mathrm{L}$ of Amylose Resin (New England BioLabs) in pull-down buffer ( $1 \times$ PBS, $0.1 \%$ Triton, $0.2 \mathrm{mM}$ PMSF, protease inhibitor). The mixture was rotated overnight at $4^{\circ} \mathrm{C}$, and, after three washes with the washing buffer $(1 \times$ PBS, $0.1 \%$ Triton, $0.2 \mathrm{mM}$ PMSF), proteins were eluted with SDS loading buffer. The samples were separated by SDS-PAGE followed by Coomassie staining.

RIPS

For RIPs from Cntl and NRDE2 knockdown cells, cells were transfected with siRNAs. Seventy-two hours after transfection, cells were resuspended by NET-2 buffer $(50 \mathrm{mM}$ Tris at $\mathrm{pH} 7.4$, $150 \mathrm{mM} \mathrm{NaCl}, 0.1 \%$ NP-40, $0.2 \mathrm{mM}$ PMSF), followed by sonication and centrifugation. The lysates were incubated with MTR4 antibody for $2 \mathrm{~h}$ at $4^{\circ} \mathrm{C}$, followed by rotation with nProtein $\mathrm{A}$ Sepharose (GE Healthcare) for another $2 \mathrm{~h}$ at $4^{\circ} \mathrm{C}$. The beads were washed three times with the NET-2 buffer. The immunoprecipitated RNA was extracted by TRI reagent (Sigma-Aldrich).
RNA-seq

For rRNA-depleted RNA-seq, RNA was isolated from nuclear fraction with TRI reagent (Sigma-Aldrich). Four micrograms of total RNA was depleted with rRNA, and stranded cDNA libraries were generated with TruSeq Stranded Total RNA Sample Prep Kit (Illumina) according to the manufacturer's instructions. For MTR4 RIP-seq, stranded cDNA libraries were generated with TruSeq Stranded Total RNA Sample Prep Kit (Illumina). RNAseq was performed on an Illumina HiSeq X Ten using a doubleread protocol of 300 cycles at Geneseeq, with a 150-nt run length.

\section{Data analysis}

RNA-seq and RIP-seq reads containing adaptors were trimmed with cutadapt (Martin 2011) program, and reads $<10$ bp were discarded. The remaining reads were then mapped to the human genome (hg19), including splicing junctions from GENCODE gene annotation (v19) with STAR (Martin 2011). Reads mapping to multiple independent genomic locations were assigned to the most abundant biotype of the locations. Genome annotations from RefSeq and ENSEMBL were downloaded from the UCSC genome browser website. For total RNA-seq, edgeR (Robinson et al. 2010) was used to identify differentially expressed genes. For nuclear RNA-seq, low abundance (CPM $<1$ between two replicates) or predominantly cytoplasmic transcripts (CPM ratio of whole cell/nuclear $>3$ ) were removed from the nuclear data set, and significant changes $(P<0.05$ and fold change $>1.5)$ that occur in total RNA-seq were filtered out. Transcripts with at least 1.5 -fold net increase in nuclear abundance were considered nuclear retained. Additionally, retained introns were analyzed by IRFounder (Middleton et al. 2017).

\section{Nuclear fraction preparation}

Nuclear fraction preparation was performed as previously described (Fan et al. 2017). Briefly, cells were suspended in hypotonic buffer (10 mM HEPES at pH 7.9, $1.5 \mathrm{mM} \mathrm{MgCl}_{2}, 10 \mathrm{mM} \mathrm{KCl}$, $0.2 \mathrm{mM}$ PMSF, $0.5 \mathrm{mM}$ DTT) and incubated for $10 \mathrm{~min}$ on ice. The swollen cells were dounced followed by centrifugation. Resuspended the pellet slowly by $1 / 2$ packed nuclear volume (PNV) of low-salt buffer (20 mM HEPES at pH 7.9, $1.5 \mathrm{mM} \mathrm{MgCl}_{2}$, $20 \mathrm{mM} \mathrm{KCl}, 0.2 \mathrm{mM}$ EDTA, 25\% glycerol, $0.2 \mathrm{mM}$ PMSF, $0.5 \mathrm{mM}$ DTT). After that, added $1 / 2 \mathrm{PNV}$ of high-salt buffer $(20$ $\mathrm{mM} \mathrm{HEPES}$ at $\mathrm{pH} 7.9,1.5 \mathrm{mM} \mathrm{MgCl}_{2}, 1.4 \mathrm{M} \mathrm{KCl}, 0.2 \mathrm{mM}$ EDTA, 25\% glycerol, 0.2 mM PMSF, $0.5 \mathrm{mM} \mathrm{DTT}$ ) into the mixture. The mixture was rotated for $30 \mathrm{~min}$ at $4^{\circ} \mathrm{C}$ followed by centrifugation and the supernatant is the nuclear extract. Total RNAs of nuclear extract were extracted by TRI reagent (SigmaAldrich).

Crystallization, data collection, and structure determination

The purified NRDE2 $2^{\text {MID }}-$ MTR $4^{71-1042}$ complex or the apoMTR $4^{71-1042}$ protein was mixed with $1 \mathrm{mM}$ ADP before crystallization. All crystals were made by the hanging-drop vapor diffusion method. The crystallization reservoir solution for NRDE2 ${ }^{\text {MID }}$-MTR $4^{71-1042}$ complex was $50 \mathrm{mM}$ glycine ( $\mathrm{pH}$ 9.0), $100 \mathrm{mM} \mathrm{NaCl}$, and $33 \%(\mathrm{w} / \mathrm{v})$ polyethylene glycol 300 (PEG $300)$, and for apo-MTR4 ${ }^{71-1042}$ was $15 \mathrm{mM}$ Tris $(\mathrm{pH} 8.5)$ and $12 \%(\mathrm{w} / \mathrm{v})$ PEG 4000 . Crystals were flash-frozen in liquid nitrogen in a cryo-protectant made of the reservoir solution supplemented with $25 \%$ ethylene glycol.

The diffraction data were collected at the Shanghai SSRF BL19U1 beamline at 100K. The data were processed with HKL3000 (Minor et al. 2006). The NRDE2 ${ }^{\text {MID }}-M T R 4^{71-1042}$ 
complex structure was determined by molecular replacement with Phaser (McCoy et al. 2007) using individual domains of yeast MTR4 as the search model (Protein Data Bank [PDB] 4U4C). The apo-MTR $4^{71-1042}$ structure was solved by molecular replacement using individual domains of MTR4 in the NRDE2 $2^{\text {MID }}$ MTR $4^{71-1042}$ complex structure as the search models. Iterative cycles of manual refitting and crystallographic refinement were performed using COOT (Emsley et al. 2010) and Phenix (Adams et al. 2002). The wwPDB Validation Service was used for the validation of the crystal structure (https://validate-rcsb-2.wwpdb .org). All figures for the molecular models were prepared using the PyMOL program (https://www.pymol.org/2). Statistics of diffraction data processing and structure refinement are shown in Supplemental Table S1.

\section{Semiquantitative MS}

Proteins were tryptic digested before passing through the C18 column packed with 1.9umAqua C18 material (Phenomenex). Peptides eluted from the LC column were directly electrosprayed into a Q-Exactive plus mass spectrometer (ThermoFisher, San Jose, CA). MS scan functions and HPLC solvent gradients were controlled by the Xcalibur data system (ThermoFisher). All raw files were processed using Maxquant software (version 1.5.3.30) (Beer et al. 2017) for feature detection, database searching, and protein/peptide quantification. MS/MS spectra were searched against the UniProtKB/Swiss-Prot human database (containing 20,386 reviewed sequences). The minimum peptide length was seven amino acids, and maximum peptide mass was $4600 \mathrm{Da}$. The allowed missed cleavages for each peptide was two. The second peptide search was activated to identify coeluting and cofragmented peptides from one MS/MS spectrum. Both peptides and proteins were filtered with a maximum FDR of 0.01 . LFQ calculations were performed separately in each parameter group. Both unique and razor peptides were selected for protein quantification. Other unmentioned parameters were the default settings of the Maxquant software (Beer et al. 2017).

\section{Electrophoretic mobility shift assay (EMSA)}

Various concentrations of protein were incubated individually with the RNAs for $30 \mathrm{~min}$ on ice in the protein buffer $(20 \mathrm{mM}$ Tris at $\mathrm{pH} 8.0,150 \mathrm{mM} \mathrm{NaCl}, 1 \%$ [v/v] glycerol, $1 \mathrm{mM}$ TCEP) containing $8 \mathrm{mM} \mathrm{MgCl}_{2}, 4 \mathrm{U}$ RNase inhibitor, and AMPPNP. After incubation, protein-bound and free RNA were separated by electrophoresis on nondenaturing $5 \%$ polyacrylamide gels (29:1) with TBE running buffer. Fluorescein-labeled RNA was detected by FluorChem M System (ProteinSimple). The sequences of the RNAs used for EMSA were listed in Supplemental Table S4.

\section{Gel-shift helicase assay}

Gel-shift helicase assay was carried out as described (Puno and Lima 2018). Briefly, RNA duplexes were prepared from oligonucleotide (Integrated DNA Technologies) in annealing buffer containing $20 \mathrm{mM}$ Tris $(\mathrm{pH} 7.0)$ and $100 \mathrm{mM}$ potassium acetate. Proteins were individually incubated with RNA duplexes in the protein dialysis buffer $(20 \mathrm{mM}$ Tris at $\mathrm{pH} 8.0,150 \mathrm{mM} \mathrm{NaCl}$, $1 \%$ [v/v] glycerol, $1 \mathrm{mM} \mathrm{TCEP}$ ) for $5 \mathrm{~min}$ at $30^{\circ} \mathrm{C}$. Unwinding reaction was initiated by adding $2 \mathrm{mM}$ ATP (pH 7.0), $2 \mathrm{mM} \mathrm{MgCl}_{2}$, and $400 \mathrm{nM}$ DNA capture strand. Unwinding reaction was stopped using $0.5 \%$ SDS, $5 \mathrm{mM}$ EDTA, and $10 \%$ glycerol. RNAs were separated by electrophoresis on $5 \%$ polyacrylamide gels (29:1) with TBE running buffer. The oligonucleotides used for helicase assay are listed in Supplemental Table S4.

Accession numbers

The accession numbers for the structure reported in this study are PDB 6IEH and 6IEG. All sequencing data have been deposited to the Gene Expression Omnibus as GSE120206.

\section{Acknowledgments}

We thank Ying Huang for providing fluorescein-labeled RNA. We thank Dangsheng Li and Xiangdong Fu for useful discussion and suggestions on this work. We thank Lingling Zhang for technical help on ESC phenotype characterization. This work was supported by grants from the National Natural Science Foundation of China (31770880, 31570822, and 31800686) to H.C., and the National Key R\&D Program of China (2017YFA0504400), the "Strategic Priority Research Program" of the Chinese Academy of Sciences (XDB19000000), and the National Science Foundation of China (31270769) to C.Y.

Author contributions: H.C., C.Y., J.L., and Y.Z. conceived of and designed the work. X.D., X.W., S.G., G.L., C.C.L.W., and Y.Z. performed data analysis. J.W., J.C., G.W., H.Z., S.C., L.Z., K.W., J.F., S.Z., B.K., P.Z., B.C., and L.W. performed the experiments. H.C. and C.Y. wrote the manuscript.

\section{References}

Adams PD, Grosse-Kunstleve RW, Hung LW, Ioerger TR, McCoy AJ, Moriarty NW, Read RJ, Sacchettini JC, Sauter NK, Terwilliger TC. 2002. PHENIX: building new software for automated crystallographic structure determination. Acta Crystallogr D Biol Crystallogr 58: 1948-1954. doi:10.1107/ S0907444902016657

Andersen PR, Domanski M, Kristiansen MS, Storvall H, Ntini E, Verheggen C, Schein A, Bunkenborg J, Poser I, Hallais M, et al. 2013. The human cap-binding complex is functionally connected to the nuclear RNA exosome. Nat Struct Mol Biol 20: 1367-1376. doi:10.1038/nsmb.2703

Anderson JS, Parker RP. 1998. The $3^{\prime}$ to $5^{\prime}$ degradation of yeast mRNAs is a general mechanism for mRNA turnover that requires the SKI2 DEVH box protein and $3^{\prime}$ to $5^{\prime}$ exonucleases of the exosome complex. EMBO J 17: 1497-1506. doi:10 .1093/emboj/17.5.1497

Beer LA, Liu P, Ky B, Barnhart KT, Speicher DW. 2017. Efficient quantitative comparisons of plasma proteomes using labelfree analysis with MaxQuant. Methods Mol Biol 1619: 339352. doi:10.1007/978-1-4939-7057-5_23

Carter KC, Taneja KL, Lawrence JB. 1991. Discrete nuclear domains of poly(A) RNA and their relationship to the functional organization of the nucleus. J Cell Biol 115: 1191-1202. doi:10 $.1083 /$ jcb.115.5.1191

Chi B, Wang Q, Wu G, Tan M, Wang L, Shi M, Chang X, Cheng H. 2013. Aly and THO are required for assembly of the human TREX complex and association of TREX components with the spliced mRNA. Nucleic Acids Res 41: 1294-1306. doi:10 $.1093 / \mathrm{nar} / \mathrm{gks} 1188$

Chi B, Wang K, Du Y, Gui B, Chang X, Wang L, Fan J, Chen S, Wu $\mathrm{X}, \mathrm{Li} \mathrm{G}$, et al. 2014. A Sub-Element in PRE enhances nuclear export of intronless mRNAs by recruiting the TREX complex via ZC3H18. Nucleic Acids Res 42: 7305-7318. doi:10.1093/ nar/gku350 
Conrad KS, Hurley JM, Widom J, Ringelberg CS, Loros JJ, Dunlap JC, Crane BR. 2016. Structure of the frequency-interacting RNA helicase: a protein interaction hub for the circadian clock. EMBO I 35: 1707-1719. doi:10.15252/embj.201694327

Dias AP, Dufu K, Lei H, Reed R. 2010. A role for TREX components in the release of spliced mRNA from nuclear speckle domains. Nat Commun 1: 97. doi:10.1038/ncomms1103

Emsley P, Lohkamp B, Scott WG, Cowtan K. 2010. Features and development of Coot. Acta Crystallogr D Biol Crystallogr 66: 486-501. doi:10.1107/S0907444910007493

Falk S, Weir JR, Hentschel J, Reichelt P, Bonneau F, Conti E. 2014. The molecular architecture of the TRAMP complex reveals the organization and interplay of its two catalytic activities. Mol Cell 55: 856-867. doi:10.1016/j.molcel.2014.07.020

Falk S, Tants JN, Basquin J, Thoms M, Hurt E, Sattler M, Conti E. 2017. Structural insights into the interaction of the nuclear exosome helicase Mtr4 with the preribosomal protein Nop53. RNA 23: 1780-1787. doi:10.1261/rna.062901.117

Fan J, Kuai B, Wu G, Wu X, Chi B, Wang L, Wang K, Shi Z, Zhang H, Chen S, et al. 2017. Exosome cofactor hMTR4 competes with export adaptor ALYREF to ensure balanced nuclear RNA pools for degradation and export. EMBO J 36: 28702886. doi:10.15252/embj.201696139

Fan J, Kuai B, Wang K, Wang L, Wang Y, Wu X, Chi B, Li G, Cheng H. 2018. mRNAs are sorted for export or degradation before passing through nuclear speckles. Nucleic Acids Res 46: 8404-8416. doi:10.1093/nar/gky650

Giacometti S, Benbahouche NEH, Domanski M, Robert MC, Meola N, Lubas M, Bukenborg J, Andersen JS, Schulze WM, Verheggen C, et al. 2017. Mutually exclusive CBC-containing complexes contribute to RNA fate. Cell Rep 18: 2635-2650. doi:10.1016/j.celrep.2017.02.046

Halbach F, Rode M, Conti E. 2012. The crystal structure of S. cerevisiae Ski2, a DExH helicase associated with the cytoplasmic functions of the exosome. RNA 18: 124-134. doi:10 $.1261 /$ rna.029553.111

Hallais M, Pontvianne F, Andersen PR, Clerici M, Lener D, Benbahouche Nel H, Gostan T, Vandermoere F, Robert MC, Cusack S, et al. 2013. CBC-ARS2 stimulates $3^{\prime}$-end maturation of multiple RNA families and favors cap-proximal processing. Nat Struct Mol Biol 20: 1358-1366. doi:10.1038/ nsmb. 2720

Houseley J, LaCava J, Tollervey D. 2006. RNA-quality control by the exosome. Nat Rev Mol Cell Biol 7: 529-539. doi:10.1038/ nrm1964

Hrossova D, Sikorsky T, Potesil D, Bartosovic M, Pasulka J, Zdrahal Z, Stefl R, Vanacova S. 2015. RBM7 subunit of the NEXT complex binds U-rich sequences and targets 3 '-end extended forms of snRNAs. Nucleic Acids Res 43: 4236-4248. doi:10.1093/nar/gkv240

Huang S, Deerinck TJ, Ellisman MH, Spector DL. 1994. In vivo analysis of the stability and transport of nuclear poly(A)+ RNA. J Cell Biol 126: 877-899. doi:10.1083/jcb.126.4.877

Jackson RN, Klauer AA, Hintze BJ, Robinson H, van Hoof A, Johnson SJ. 2010. The crystal structure of Mtr4 reveals a novel arch domain required for rRNA processing. EMBO J 29: 2205-2216. doi:10.1038/emboj.2010.107

Jia H, Wang X, Anderson JT, Jankowsky E. 2012. RNA unwinding by the Trf4/Air2/Mtr4 polyadenylation (TRAMP) complex. Proc Natl Acad Sci 109: 7292-7297. doi:10.1073/pnas .1201085109

LaCava J, Houseley J, Saveanu C, Petfalski E, Thompson E, Jacquier A, Tollervey D. 2005. RNA degradation by the exosome is promoted by a nuclear polyadenylation complex. Cell 121: 713-724. doi:10.1016/j.cell.2005.04.029
Lubas M, Christensen MS, Kristiansen MS, Domanski M, Falkenby LG, Lykke-Andersen S, Andersen JS, Dziembowski A, Jensen TH. 2011. Interaction profiling identifies the human nuclear exosome targeting complex. Mol Cell 43: 624-637. doi:10.1016/j.molcel.2011.06.028

Martin M. 2011. Cutadapt removes adapter sequences from highthroughput sequencing reads. EMBnet.journal 17: 10. doi:10 $.14806 /$ ej.17.1.200

McCoy AJ, Grosse-Kunstleve RW, Adams PD, Winn MD, Storoni LC, Read RJ. 2007. Phaser crystallographic software. I Appl Crystallogr 40: 658-674. doi:10.1107/S0021889807021206

Meola N, Domanski M, Karadoulama E, Chen Y, Gentil C, Pultz D, Vitting-Seerup K, Lykke-Andersen S, Andersen JS, Sandelin A, et al. 2016. Identification of a nuclear exosome decay pathway for processed transcripts. Mol Cell 64: 520-533. doi:10 .1016/j.molcel.2016.09.025

Middleton R, Gao D, Thomas A, Singh B, Au A, Wong JJ, Bomane A, Cosson B, Eyras E, Rasko JE, et al. 2017. IRFinder: assessing the impact of intron retention on mammalian gene expression. Genome Biol 18: 51. doi:10.1186/s13059-017-1184-4

Minor W, Cymborowski M, Otwinowski Z, Chruszcz M. 2006. $H K L-3000$ : the integration of data reduction and structure solution-from diffraction images to an initial model in minutes. Acta Crystallogr D Biol Crystallogr 62: 859-866. doi:10.1107/ S0907444906019949

Molleston JM, Sabin LR, Moy RH, Menghani SV, Rausch K, Gordesky-Gold B, Hopkins KC, Zhou R, Jensen TH, Wilusz JE, et al. 2016. A conserved virus-induced cytoplasmic TRAMPlike complex recruits the exosome to target viral RNA for degradation. Genes Dev 30: 1658-1670. doi:10.1101/gad.284604 .116

Mor A, White A, Zhang K, Thompson M, Esparza M, Muñoz-Moreno R, Koide K, Lynch KW, Garcia-Sastre A, Fontoura BM. 2016. Influenza virus mRNA trafficking through host nuclear speckles. Nat Microbiol 1: 16069. doi:10.1038/nmicrobiol .2016 .69

Ogami K, Manley JL. 2017. Mtr4/ZFC3H1 protects polysomes through nuclear RNA surveillance. Cell Cycle 16: 19992000. doi:10.1080/15384101.2017.1377501

Ogami K, Richard P, Chen Y, Hoque M, Li W, Moresco JJ, Yates JR III, Tian B, Manley JL. 2017. An Mtr4/ZFC3H1 complex facilitates turnover of unstable nuclear RNAs to prevent their cytoplasmic transport and global translational repression. Genes Dev 31: 1257-1271. doi:10.1101/gad.302604.117

Puno MR, Lima CD. 2018. Structural basis for MTR4-ZCCHC8 interactions that stimulate the MTR4 helicase in the nuclear exosome-targeting complex. Proc Natl Acad Sci 115: E5506E5515. doi:10.1073/pnas.1803530115

Richard P, Ogami K, Chen Y, Feng S, Moresco JJ, Yates JR III, Manley JL. 2018. NRDE-2, the human homolog of fission yeast Nrl1, prevents DNA damage accumulation in human cells. RNA Biol 15: 868-876. doi:10.1080/15476286.2018.1467180

Robinson MD, McCarthy DJ, Smyth GK. 2010. edgeR: a Bioconductor package for differential expression analysis of digital gene expression data. Bioinformatics 26: 139-140. doi:10 .1093/bioinformatics/btp616

San Paolo S, Vanacova S, Schenk L, Scherrer T, Blank D, Keller W, Gerber AP. 2009. Distinct roles of non-canonical poly(A) polymerases in RNA metabolism. PLoS Genet 5: e1000555. doi:10 .1371 /journal.pgen.1000555

Schmidt C, Kowalinski E, Shanmuganathan V, Defenouillere Q, Braunger K, Heuer A, Pech M, Namane A, Berninghausen O, Fromont-Racine M, et al. 2016. The cryo-EM structure of a ribosome-Ski2-Ski3-Ski8 helicase complex. Science 354: 14311433. doi:10.1126/science.aaf7520 
Schuller JM, Falk S, Fromm L, Hurt E, Conti E. 2018. Structure of the nuclear exosome captured on a maturing preribosome. Science 360: 219-222. doi:10.1126/science.aar5428

Shcherbik N, Wang M, Lapik YR, Srivastava L, Pestov DG. 2010. Polyadenylation and degradation of incomplete RNA polymerase I transcripts in mammalian cells. EMBO Rep 11: 106-111. doi:10.1038/embor.2009.271

Silla T, Karadoulama E, Mạkosa D, Lubas M, Jensen TH. 2018. The RNA exosome adaptor $\mathrm{ZFC} 3 \mathrm{H} 1$ functionally competes with nuclear export activity to retain target transcripts. Cell Rep 23: 2199-2210. doi:10.1016/j.celrep.2018.04.061

Strässer K, Hurt E. 2000. Yralp, a conserved nuclear RNA-binding protein, interacts directly with Mex67p and is required for mRNA export. EMBO J 19: 410-420. doi:10.1093/emboj/ 19.3.410

Taylor LL, Jackson RN, Rexhepaj M, King AK, Lott LK, van Hoof A, Johnson SJ. 2014. The Mtr4 ratchet helix and arch domain both function to promote RNA unwinding. Nucleic Acids Res 42: 13861-13872. doi:10.1093/nar/gku1208

Thoms M, Thomson E, Baßler J, Gnädig M, Griesel S, Hurt E. 2015. The exosome is recruited to RNA substrates through specific adaptor proteins. Cell 162: 1029-1038. doi:10.1016/j cell.2015.07.060

Vaňáčová Š, Wolf J, Martin G, Blank D, Dettwiler S, Friedlein A, Langen H, Keith G, Keller W. 2005. A new yeast poly(A) polymerase complex involved in RNA quality control. PLOS Biol3: e189. doi:10.1371/journal.pbio.0030189
Vasiljeva L, Buratowski S. 2006. Nrd1 interacts with the nuclear exosome for $3^{\prime}$ processing of RNA polymerase II transcripts. Mol Cell 21: 239-248. doi:10.1016/j.molcel.2005.11.028

Visa N, Puvion-Dutilleul F, Bachellerie JP, Puvion E. 1993. Intranuclear distribution of U1 and U2 snRNAs visualized by high resolution in situ hybridization: revelation of a novel compartment containing U1 but not U2 snRNA in HeLa cells. Eur $I$ Cell Biol 60: 308-321.

Wang K, Wang L, Wang J, Chen S, Shi M, Cheng H. 2018. Intronless mRNAs transit through nuclear speckles to gain export competence. I Cell Biol 217: 3912-3929. doi:10.1083/jcb .201801184

Weick EM, Puno MR, Januszyk K, Zinder JC, DiMattia MA, Lima CD. 2018. Helicase-dependent RNA decay illuminated by a Cryo-EM structure of a human nuclear RNA exosomeMTR4 complex. Cell 173: 1663-1677 e1621. doi:10.1016/j .cell.2018.05.041

Weir JR, Bonneau F, Hentschel J, Conti E. 2010. Structural analysis reveals the characteristic features of Mtr4, a DExH helicase involved in nuclear RNA processing and surveillance. Proc Natl Acad Sci 107: 12139-12144. doi:10.1073/ pnas. 1004953107

Wyers F, Rougemaille M, Badis G, Rousselle JC, Dufour ME, Boulay J, Régnault B, Devaux F, Namane A, Séraphin B, et al. 2005. Cryptic pol II transcripts are degraded by a nuclear quality control pathway involving a new poly(A) polymerase. Cell 121: 725-737. doi:10.1016/j.cell.2005.04.030 


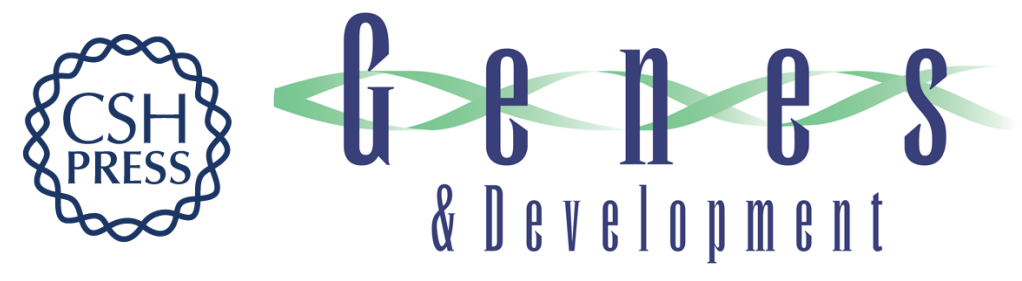

\section{NRDE2 negatively regulates exosome functions by inhibiting MTR4 recruitment and exosome interaction}

Jianshu Wang, Jiyun Chen, Guifen Wu, et al.

Genes Dev. 2019, 33: originally published online March 6, 2019

Access the most recent version at doi:10.1101/gad.322602.118

\section{Supplemental http://genesdev.cshlp.org/content/suppl/2019/03/04/gad.322602.118.DC1 Material}

References This article cites 51 articles, 15 of which can be accessed free at: http://genesdev.cshlp.org/content/33/9-10/536.full.html\#ref-list-1

Creative This article is distributed exclusively by Cold Spring Harbor Laboratory Press for the first Commons six months after the full-issue publication date (see

License http://genesdev.cshlp.org/site/misc/terms.xhtml). After six months, it is available under a Creative Commons License (Attribution-NonCommercial 4.0 International), as described at http://creativecommons.org/licenses/by-nc/4.0/.

Email Alerting Receive free email alerts when new articles cite this article - sign up in the box at the top Service right corner of the article or click here.

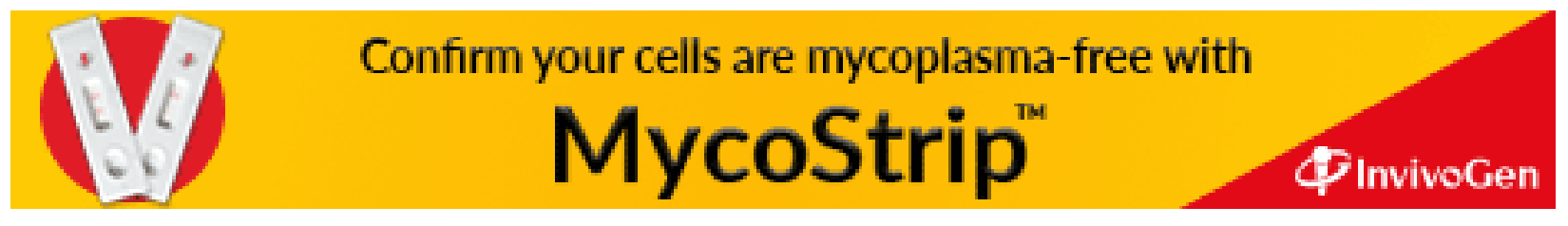

